\title{
Modeled larval connectivity of a multi-species reef fish and invertebrate assemblage off the coast of Moloka'i, Hawai' $i$
}

\author{
Emily E Conklin ${ }^{\text {Corresp., }}{ }^{1}$, Anna B Neuheimer ${ }^{2,3}$, Robert J Toonen ${ }^{1}$ \\ ${ }^{1}$ Hawai'i Institute of Marine Biology, University of Hawai'i at Mānoa, Kāne'ohe, Hawai'i \\ 2 Department of Oceanography, University of Hawai'i at Mānoa, Honolulu, Hawai'i \\ 3 Aarhus Institute of Advanced Studies (AIAS), Aarhus University, Aarhus, Denmark \\ Corresponding Author: Emily E Conklin \\ Email address: conkline@hawaii.edu
}

We use a novel individual-based model (IBM) to simulate larval dispersal around the island of Moloka'i in the Hawaiian Archipelago. Our model uses ocean current output from the Massachusetts Institute of Technology general circulation model (MITgcm) as well as biological data on four invertebrate and seven fish species of management relevance to produce connectivity maps among sites around the island of Moloka'i. These 11 species span the range of life history characteristics of Hawaiian coral reef species and show different spatial and temporal patterns of connectivity as a result. As expected, the longer the pelagic larval duration (PLD), the greater the proportion of larvae that disperse longer distances, but regardless of PLD (3 - 270d) most successful dispersal occurs either over short distances within an island $(<30 \mathrm{~km})$ or to adjacent islands $(50-125 \mathrm{~km})$. Again, regardless of PLD, around the island of Moloka'i, connectivity tends to be greatest among sites along the same coastline and exchange between northward, southward, eastward and westward-facing shores is limited. Using a graph-theoretic approach to visualize the data, we highlight that the eastern side of the island tends to show the greatest outdegree and betweenness centrality, which indicate important larval sources and connectivity pathways for the rest of the island. The marine protected area surrounding Kalaupapa National Historical Park emerges as a potential source for between-island larval connections, and the west coast of the Park is one of the few regions on Moloka' $i$ that acts as a net larval source across all species. Using this IBM and visualization approach reveals patterns of exchange between habitat regions and highlights critical larval sources and multi-generational pathways to indicate priority areas for marine resource managers. 
1 Modeled larval connectivity of a multi-species reef fish and

2 invertebrate assemblage off the coast of Moloka'i, Hawai'i

3 Emily E. Conklin ${ }^{1}$, Anna B. Neuheimer ${ }^{2,3}$, Robert J. Toonen ${ }^{1}$

4 'Hawai'i Institute of Marine Biology, University of Hawai'i at Mānoa, 46-007 Lilipuna Road,

5 Kāne'ohe, HI 96744

6 2Department of Oceanography, University of Hawai'i at Mānoa, 1000 Pope Road, Marine

7 Science Building, Honolulu, HI 9682

$8{ }^{3}$ Aarhus Institute of Advanced Studies (AIAS), Aarhus University, DK-8000 Aarhus C, Denmark

10 Corresponding author:

11 Emily E. Conklin ${ }^{1}$

12

13 Email address:

14 conkline@hawaii.edu 
15

16

17

18

19

20

21

22

23

24

25

26

27

28

29

30

31

32

33

34

35

36

37

38

39

40

41

42

43

44

45

46

47

48

49

50

51

52

53

54

55

56

57

58

\section{Abstract:}

We use a novel individual-based model (IBM) to simulate larval dispersal around the island of Moloka'i in the Hawaiian Archipelago. Our model uses ocean current output from the Massachusetts Institute of Technology general circulation model (MITgcm) as well as biological data on four invertebrate and seven fish species of management relevance to produce connectivity maps among sites around the island of Moloka'i. These 11 species span the range of life history characteristics of Hawaiian coral reef species and show different spatial and temporal patterns of connectivity as a result. As expected, the longer the pelagic larval duration (PLD), the greater the proportion of larvae that disperse longer distances, but regardless of PLD ( $3-270$ days) most successful dispersal occurs either over short distances within an island $(<30 \mathrm{~km})$ or to adjacent islands (50-125 km). Again, regardless of PLD, around the island of Moloka' $\mathrm{i}$, connectivity tends to be greatest among sites along the same coastline and exchange between northward, southward, eastward and westward-facing shores is limited. Using a graph-theoretic approach to visualize the data, we highlight that the eastern side of the island tends to show the greatest out-degree and betweenness centrality, which indicate important larval sources and connectivity pathways for the rest of the island. The marine protected area surrounding Kalaupapa National Historical Park emerges as a potential source for between-island larval connections, and the west coast of the Park is one of the few regions on Moloka'i that acts as a net larval source across all species. This IBM approach reveals patterns of exchange between habitat regions and highlights critical larval sources and multi-generational pathways to indicate priority areas for marine resource managers.

\section{Introduction:}

Knowledge of population connectivity is necessary for effective management in marine environments (Mitarai, Siegel, \& Winters, 2008; Botsford et al., 2009; Toonen et al., 2011). For many species of marine invertebrate and reef fish, dispersal is mostly limited to the pelagic larval life stage. Therefore, an understanding of larval dispersal patterns is critical for studying population dynamics, connectivity, and conservation in the marine environment (Jones, Srinivasan, \& Almany, 2007; Lipcius et al., 2008; Gaines et al., 2010; Toonen et al., 2011). Many coastal and reef species have a bi-phasic life history in which adults display limited geographic range and high site fidelity, while larvae are pelagic and highly mobile (Thorson, 1950; Scheltema, 1971; Strathmann, 1993; Marshall et al., 2012). This life history strategy is not only common to sessile invertebrates such as corals or limpets; many reef fish species have been shown to have a home range of $<1 \mathrm{~km}$ as adults (Meyer et al., 2000; Meyer, Papastamatiou, \& Clark, 2010). Depending on species, the mobile planktonic stage can last from hours to months and has the potential to transport larvae up to hundreds of kilometers away from a site of origin (Scheltema, 1971; Richmond, 1987; Shanks, 2009). Knowledge of larval dispersal patterns can be used to inform effective management, such as marine spatial management strategies that sustain source populations of breeding individuals capable of dispersing offspring to other areas.

Both biological and physical factors impact larval dispersal, although the relative importance of these factors is likely variable among species and sites and remains debated (Levin, 2006; Paris, Chérubin, \& Cowen, 2007; Cowen \& Sponaugle, 2009; White et al., 2010). In situ data on pelagic larvae are sparse; marine organisms at this life stage are difficult to capture and identify, and are typically found in low densities across large areas of the open ocean (Clarke, 1991; Wren \& Kobayashi, 2016). A variety of genetic and chemistry techniques have 
59 therefore been developed to estimate larval connectivity (Gillanders 2005; Leis et al., 2011;

60 Toonen et al., 2011; Johnson et al., 2018). Computer models informed by field and laboratory

61 data have also become a valuable tool for estimating larval dispersal and population connectivity

62 (Paris, Chérubin, \& Cowen, 2007; Botsford et al., 2009; Sponaugle et al., 2012; Kough, Paris, \&

63 Butler, 2013; Wood et al., 2014). Individual-based models, or IBMs, can incorporate both

64 biological and physical factors known to influence larval movement. Pelagic larval duration

65 (PLD), for example, is the amount of time a larva spends in the water column before settlement and can vary widely among or even within species (Toonen \& Pawlik, 2001). PLD affects how far an individual can be successfully transported by ocean currents, and so is expected to directly affect connectivity patterns (Siegel et al., 2003; Shanks, 2009; Dawson et al., 2014). In addition to PLD, adult reproductive strategy and timing (Carson et al., 2010; Portnoy et al., 2013), fecundity (Castorani et al., 2017), larval mortality (Vikebø et al., 2007), and larval developmental, morphological, and behavioral characteristics (Paris, Chérubin, \& Cowen, 2007) may all play a role in shaping connectivity patterns. Physical factors such as temperature, bathymetry, and current direction can also substantially influence connectivity (Cowen \& Sponaugle, 2009). In this study, we incorporated both biotic and abiotic components in an IBM coupled with an oceanographic model to predict fine-scale patterns of larval exchange around the island of Moloka' $i$ in the Hawaiian archipelago.

The main Hawaiian Islands are located in the middle of the North Pacific Subtropical Gyre, and are bordered by the North Hawaiian Ridge current along the northern coasts of the islands and the Hawaii Lee Current along the southern coasts, both of which run east to west and are driven by the prevailing easterly trade winds (Lumpkin, 1998, Friedlander et al., 2005). The Hawai' $i$ Lee Countercurrent, which runs along the southern perimeter of the chain, flows west to east (Lumpkin, 1998). The pattern of mesoscale eddies around the islands is complex and varies seasonally (Friedlander et al., 2005; Vaz et al., 2013).

Hawaiian marine communities face unprecedented pressures, including coastal development, overexploitation, disease, and increasing temperature and acidification due to climate change (Smith, 1993; Lowe, 1995; Coles \& Brown, 2003; Friedlander et al., 2003; Friedlander et al., 2005; Aeby, 2006). Declines in Hawaiian marine resources argue for implementation of a more holistic approach than traditional single-species maximum sustainable yield techniques, which have proven ineffective (Goodyear, 1996; Hilborn, 2011). There is a general movement toward the use of ecosystem-based management, which requires knowledge of ecosystem structure and connectivity patterns to establish and manage marine spatial planning areas (Slocombe, 1993; Browman et al., 2004; Pikitch et al., 2004; Arkema, Abramson, \& Dewsbury, 2006). Kalaupapa National Historical Park is a federal marine protected area (MPA) located on the north shore of Moloka' $i$, an island in the Maui Nui complex of the Hawaiian archipelago, that includes submerged lands and waters up to $1 / 4$ mile offshore (NOAA, 2009). At least five IUCN red-listed coral species have been identified within this area (Kenyon, Maragos, \& Fenner, 2011), and in 2010 the Park showed the greatest fish biomass and species diversity out of four Hawaiian National Parks surveyed (Beets, Brown, \& Friedlander, 2010). One of the major benefits expected of MPAs is that the protected waters within the area provide a source of larval spillover to other sites on the island, seeding these areas for commercial, recreational, and subsistence fishing (McClanahan \& Mangi, 2000; Halpern \& Warner, 2003; Lester et al., 2009). In this study, we used a Lagrangian particle-tracking IBM (Wong-Ala et al., 2018) to simulate larval dispersal around Moloka' $i$ and to estimate the larval exchange among sites at the scale of an individual island. We have parameterized our model with biological data for eleven 
105

106

107

108

109

110

111

112

113

114

115

116

117

118

119

120

121

122

123

124

125

126

127

128

129

130

131

132

133

134

135

136

137

138

139

140

141

142

143

144

145

146

147

species covering a breadth of Hawaiian reef species life histories (e.g. habitat preferences, larval behaviors, and pelagic larval durations, Table 1), and of interest to both the local community and resource managers. Our goals were to examine patterns of species-specific connectivity, characterize the location and relative magnitude of connections around Moloka' $i$, describe sites of potential management relevance, and address the question of whether Kalaupapa National Historical Park provides larval spillover for adjacent sites on Moloka' $i$, or connections to the adjacent islands of Hawai'i, Maui, O`ahu, Lana'i, and Kaho'olawe.

\section{Methods:}

\section{I) Circulation model}

We selected the hydrodynamic model MITgcm, which is designed for the study of dynamical processes in the ocean on a horizontal scale. This model solves incompressible Navier-Stokes equations to describe the motion of viscous fluid on a sphere, discretized using a finite-volume technique (Marshall et al., 1997). The 1-km resolution MITgcm domain for this study extends from $198.2^{\circ} \mathrm{E}$ to $206^{\circ} \mathrm{E}$ and from $17^{\circ} \mathrm{N}$ to $22.2^{\circ} \mathrm{N}$, an area that includes the islands of Moloka'i, Maui, Lana'i, Kaho'olawe, O'ahu, and Hawai' $i$. While Ni'ihau and southern Kauai also fall within the domain, we discarded connectivity to these islands because they lie within the $0.5^{\circ}$ boundary zone of the current model. Boundary conditions are enforced over 20 grid points on all sides of the model domain. Vertically, the model is divided into 50 layers that increase in thickness with depth, from $5 \mathrm{~m}$ at the surface $(0.0-5.0 \mathrm{~m})$ to $510 \mathrm{~m}$ at the base $(4470-4980 \mathrm{~m})$. Model variables were initialized using the output of a Hybrid Coordinate Ocean Model ( $\mathrm{HYCOM}$ ) at a horizontal resolution of $0.04^{\circ}(\sim 4 \mathrm{~km})$ configured for the main Hawaiian Islands, using the General Bathymetric Chart of the Oceans database (GEBCO, 1/60 ${ }^{\circ}$ ) (Jia et al., 2011).

The simulation runs from March $31^{\text {st }}, 2011$ to July $30^{\text {th }}, 2013$ with a temporal resolution of 24 hours and shows seasonal eddies as well as persistent mesoscale features (Fig. S1). We do not include tides in the model due to temporal resolution. Our model period represents a neutral ocean state; no El Niño or La Niña events occurred during this time period. To ground-truth the circulation model, we compared surface current output to real-time trajectories of surface drifters from the GDP Drifter Data Assembly Center (Fig. S2) (Elipot et al., 2016), as well as other current models of the area (Wren et al., 2016; Storlazzi et al., 2017).

\section{II) Biological model}

To simulate larval dispersal, we used a modified version of the Wong-Ala et al. (2018) IBM, a 3D Lagrangian particle-tracking model written in the $\mathrm{R}$ programming language (R Core Team, 2017). The model takes the aforementioned MITgcm current products as input, as well as shoreline shapefiles extracted from the full resolution NOAA Global Self-consistent Hierarchical High-resolution Geography database, v2.3.0 (Wessel \& Smith, 1996). Our model included 65 land masses within the geographic domain, the largest being the island of Hawai' $i$ and the smallest being Pu'uki'i Island, a 1.5-acre islet off the eastern coast of Maui. To model depth, we used the one arc-minute-resolution ETOPO1 bathymetry, extracted using the R package 'marmap' (Amante \& Eakins, 2009; Pante \& Simon-Bouhe, 2013).

Each species was simulated with a separate model run. Larvae were modeled from spawning to settlement and were transported at each timestep ( $t=2$ hours) by advection-diffusion transport. This transport consisted of (1) advective displacement caused by water flow, consisting of east $(u)$ and north $(v)$ velocities read from daily MITgcm files, and (2) additional 
148 random-walk displacement, using a diffusion constant of $0.2 \mathrm{~m}^{2} / \mathrm{s}^{-1}$ (Lowe et al., 2009). Vertical

149 velocities $(w)$ were not implemented by the model; details of vertical larval movement are

150 described below. Advection was interpolated between data points at each timestep using an

151 Eulerian 2D barycentric interpolation method. We chose this implementation over a more

152 computationally intensive interpolation method (i.e. $4^{\text {th }}$-order Runge-Kutta) because we did not

153 observe a difference at this timestep length. Biological processes modeled include PLD,

154 reproduction timing and location, mortality, and ontogenetic changes in vertical distribution;

155 these qualities were parameterized via species-specific data obtained from previous studies and

156 from the local fishing and management community (Table 1).

157 Larvae were released from habitat-specific spawning sites and were considered settled if

158 they fell within a roughly 1-km contour around reef or intertidal habitat at the end of their

159 pelagic larval duration. Distance from habitat was used rather than water depth because Penguin

160 Bank, a relatively shallow bank to the southwest of Moloka'i, does not represent suitable habitat

161 for reef-associated species. PLD for each larva was a randomly assigned value between the

162 minimum and maximum PLD for that species, and larvae were removed from the model if they

163 had reached their PLD and were not within a settlement zone. No data on pre-competency period

164 were available for our study species, so this parameter was not included. Mortality rates were

165 calculated as larval half-lives; e.g., one-half of all larvae were assumed to have survived at one-

166 half of the maximum PLD for that species (following Holstein, Paris, \& Mumby, 2014). Since

167 our focus was on potential connectivity pathways, reproductive rates were calibrated to allow for

168 saturation of possible settlement sites, equating from $\sim 900,000$ to $\sim 1,7000,000$ larvae released

169 depending on species. Fecundity is therefore derived not from biological data, but from

170 computational minimums.

171 Development, and resulting ontogenetic changes in behavior, is specific to the life history

172 of each species. Broadcast-spawning species with weakly-swimming larvae ( $P$. meandrina and

173 Cellana spp., Table 1) were transported as passive particles randomly distributed between $0-5 \mathrm{~m}$

174 depth (Storlazzi, Brown, \& Field, 2006). Previous studies have demonstrated that fish larvae

175 have a high degree of control over their vertical position in the water column (Irisson et al.,

176 2010; Huebert, Cowen, \& Sponaugle, 2011). Therefore, we modeled broadcast-spawning fish

177 species with a 24-hour passive buoyant phase to simulate eggs pre-hatch, followed by a pelagic

178 larval phase with a species-specific depth distribution. For C. ignoblis, C. melampygus, $P$.

179 porphyreus, $C$. perspicillatus, and $S$. rubroviolaceus, we used genus-level depth distributions

180 (Fig. S3) obtained from the 1996 NOAA ichthyoplankton vertical distributions data report

181 (Boehlert \& Mundy, 1996). P. sexfilis and C. strigosus larvae were randomly distributed between

182 50-100 m (Boehlert et al., 1992). Benthic brooding species (O. cyanea and Panulirus spp.) do

183 not have a passive buoyant phase, and thus were released as larvae randomly distributed between

$18450-100 \mathrm{~m}$. At each time step, a larva's depth was checked against bathymetry, and was assigned

185 to the nearest available layer if the species-specific depth was not available at these coordinates.

186

187

188

189

190

For data-poor species, we used congener-level estimates for PLD (see Table 1). For example, there is no estimate of larval duration for Caranx species, but in Hawai' $i$ peak spawning occurs in May-July and peak recruitment in August-December (Sudekum, 1984; Longenecker et al., 2010). In consultation with resource managers and community members, a PLD of 140 days was chosen pending future data that indicates a more accurate pelagic period.

Spawning sites were generated using data from published literature and modified after input from Native Hawaiian cultural practitioners and the Moloka'i fishing community (Fig. 1). 
194 Species-specific habitat suitability was inferred from the 2013-2016 Marine Biogeographic

195 Assessment of the Main Hawaiian Islands (Costa \& Kendall, 2016). We designated coral habitat

196 as areas with $5-90 \%$ coral cover, or $>=1$ site-specific coral species richness, for a total of 127

197 spawning sites on Moloka'i. Habitat for reef invertebrates followed coral habitat, with additional

198 sites added after community feedback for a total of 136 sites. Areas with a predicted reef fish

199 biomass of $58-1,288 \mathrm{~g} / \mathrm{m}^{2}$ were designated as reef fish habitat (Stamoulis et al., 2016), for a

200 total of 109 spawning sites. Sand habitat was designated as $90-100 \%$ uncolonized for a total of

201115 sites. Intertidal habitat was designated as any rocky shoreline area not covered by sand or

202 mud, for a total of 87 sites. Number of adults was assumed equal at all sites. For regional

203 analysis, we pooled sites into groups of 2 to 11 sites based on benthic habitat and surrounding

204 geography (Fig. 1A). Adjacent sites were grouped if they shared the same benthic habitat

205 classification and prevailing wave direction, and/or were part of the same reef tract.

206

207

208

209

210

211

212

213

214

215

216

217

218

219

220

221

222

223

224

225

226

227

228

229

230

231

232

233

234

235

236

237

238

\section{IV) Source-sink dynamics and local retention}

Dispersal distance was measured via the distm function in the R package 'geosphere', which calculates distance between geographical points via the Haversine formula (Hijmans 2016). This distance, measured between spawn and settlement locations, was used to calculate dispersal kernels to examine and compare species-specific distributions. We also measured local retention, or the percentage of successful settlers from a site that were retained at that site (i.e. settlers at site $A$ that originated from site $A$ / total successful settlers that originated from site $A$ ). To estimate the role of specific sites around Moloka' $i$, we also calculated a source-sink index for each species (Holstein, Paris, \& Mumby, 2014; Wren et al., 2016). This index defines sites as either a source, in which a site's successful export to other sites is greater than its import, or a sink, in which import from other sites is greater than successful export. It is calculated by dividing the difference between number of successfully exported and imported larvae by the sum of all successfully exported and imported larvae. A value $<0$ indicates that a site acts as a net sink, while a value $>0$ indicates that a site acts as a net source. While we measured successful dispersal to adjacent islands, we did not spawn larvae from them, and therefore these islands represent exogenous sinks. For this reason, settlement to other islands was not included in source-sink index calculations.

We also calculated settlement proportion between different regions for each species (Calabrese \& Fagan, 2004). We calculated the forward settlement proportion, i.e. the proportion of settlers from a specific settlement site $(s)$ originating from an observed origin site $(o)$, by scaling the number of successful settlers from site $o$ settling at site $s$ to all successful settlers originating from site $o$. Forward proportion can be represented as $\mathrm{P}_{s o}=\mathrm{S}_{o s} / \sum \mathrm{S}_{o}$. We also calculated rearward settlement proportion, or the proportion of settlers from a specific origin site $(o)$ observed at settlement site $(s)$, by scaling the number of settlers observed at site $s$ originating from site $o$ to all settlers observed at site $s$. Rearward proportion can be represented as $\mathrm{P}_{o s}=\mathrm{S}_{o s} /$ $\sum \mathrm{S}_{S}$.

\section{V) Graph-theoretic analysis}

To quantify connections between sites, we applied graph theory to population connectivity (Treml et al., 2008; Holstein, Paris, \& Mumby, 2014). Graph theoretic analysis is highly scalable and can be used to examine fine-scale networks between reef sites up to broadscale analyses between islands or archipelagos, mapping to both local and regional management needs. It also allows for both network- and site-specific metrics, enabling the comparison of connectivity between species and habitat sites as well as highlighting potential multi- 
239 generational dispersal corridors. Graph theory also provides a powerful tool for spatial

240 visualization, allowing for rapid, intuitive communication of connectivity results to researchers,

241 managers, and the public alike. This type of analysis can be used to model pairwise relationships

242 between spatial data points by breaking down individual-based output into a series of nodes

243 (habitat sites) and edges (directed connections between habitat sites). We then used these nodes

244 and edges to examine the relative importance of each site and dispersal pathway to the greater

245 pattern of connectivity around Moloka' $i$, as well as differences in connectivity patterns between

246 species (Treml et al., 2008; Holstein, Paris, \& Mumby, 2014). We used the R package 'igraph' to

247 examine several measures of within-island connectivity (Csardi \& Nepusz, 2006). Edge density,

248 or the proportion of realized edges out of all possible edges, is a multi-site measure of

249 connectivity. Areas with a higher edge density have more direct connections between habitat

250 sites, and thus are more strongly connected. We measured edge density along and between the

251 north, south, east, and west coasts of Moloka' $i$ to examine possible population structure and

252 degree of exchange among the marine resources of local communities.

253

254

255

256

257

258

259

260

261

262

263

264

265

266

267

268

269

270

271

272

273

274

275

276

277

278

279

280

281

282

283

284

The distribution of shortest path length is also informative for comparing overall connectivity. In graph theory, a shortest path is the minimum number of steps needed to connect two sites. For example, two sites that exchange larvae in either direction are connected by a shortest path of one, whereas if they both share larvae with an intermediate site but not with each other, they are connected by a shortest path of two. In a biological context, shortest path can correspond to number of generations needed for exchange: sites with a shortest path of two require two generations to make a connection. Average shortest path, therefore, is a descriptive statistic to estimate connectivity of a network. If two sites are unconnected, it is possible to have infinite-length shortest paths; here, these infinite values were noted but not included in final analyses.

Networks can also be broken in connected components (Csardi \& Nepusz, 2006). A weakly connected component (WCC) is a subgraph in which all nodes are not reachable by other nodes. A network split into multiple WCCs indicates separate populations that do not exchange any individuals, and a large number of WCCs indicates a low degree of island-wide connectivity. A strongly connected component (SCC) is a subgraph in which all nodes are directly connected and indicates a high degree of connectivity. A region with many small SCCs can indicate high local connectivity but low island-wide connectivity. Furthermore, component analysis can identify cut nodes, or nodes that, if removed, break a network into multiple WCCs. Pinpointing these cut nodes can identify potential important sites for preserving a population's connectivity, and could inform predictions about the impact of site loss (e.g. a large-scale coral bleaching event) on overall connectivity.

On a regional scale, it is important to note which sites are exporting larvae to, or importing larvae from, other sites. To this end, we examined in-degree and out-degree for each region. In-degree refers to the number of inward-directed edges to a specific node, or how many other sites provide larvae into site ' $A$ '. Out-degree refers to the number of outward-directed edges from a specific node, or how many sites receive larvae from site ' $A$ '. Habitat sites with a high out-degree seed a large number of other sites, and indicate potentially important larval sources, while habitat sites with a low in-degree rely on a limited number of larval sources and may therefore be dependent on connections with these few other sites to maintain population size. Finally, betweenness centrality (BC) refers to the number of shortest paths that pass through a given node, and may therefore indicate connectivity pathways or 'chokepoints' that are important to overall connectivity on a multigenerational timescale. $\mathrm{BC}$ was weighted with the 
285

286

287

288

289

290

291

292

293

294

295

296

297

298

299

300

301

302

303

304

305

306

307

308

309

310

311

312

313

314

315

316

317

318

319

320

321

322

323

324

325

326

327

proportion of dispersal as described in the preceding section. We calculated in-degree, outdegree, and weighted betweenness centrality for each region in the network for each species.

As with the source-sink index, we did not include sites on islands other than Moloka' $i$ in our calculations of edge density, shortest paths, connected components, cut nodes, in- and outdegree, or betweenness centrality in order to focus on within-island patterns of connectivity.

\section{Results}

\section{I) Effects of biological parameters on fine-scale connectivity patterns}

The species-specific parameters that were available to parameterize the dispersal models substantially influenced final output (Fig. 2). The proportion of successful settlers (either to Moloka' $i$ or to neighboring islands) varied widely by species, from $2 \%$ (Panulirus spp.) to $25 \%$ (Cellana spp.). Minimum pelagic duration and settlement success were negatively correlated (e.g. an estimated -0.79 Pearson correlation coefficient). Species modeled with batch spawning at a specific moon phase and/or time of day (Cellana spp., P. meandrina, and C. ignoblis) displayed slightly higher settlement success than similar species modeled with constant spawning over specific months. On a smaller scale, we also examined average site-scale local retention, comparing only retention to the spawning site versus other sites on Moloka'i (Fig. 2). Local retention was lowest for Caranx spp. $(<1 \%)$ and highest for $O$. cyanea and $P$. sexfilis (8.1\% and $10 \%$, respectively).

We measured network-wide connectivity via distribution of shortest paths, or the minimum number of steps between a given two nodes in a network, only including sites on Moloka'i (Fig. 2). O. cyanea and P. sexfilis showed the smallest shortest paths overall, meaning that on average, it would take fewer generations for these species to demographically bridge any given pair of sites. Using maximum shortest path, it could take these species three generations at most to connect sites. Cellana spp. and P. meandrina, by comparison, could take as many as five generations. Other medium- and long-dispersing species showed relatively equivalent shortestpath distributions, with trevally species showing the highest mean path length and therefore the lowest island-scale connectivity.

The number and size of weakly-connected and strongly-connected components in a network is also an informative measure of connectivity (Fig. 2). No species in our study group was broken into multiple weakly-connected components; however, there were species-specific patterns of strongly connected sites. $O$. cyanea and $P$. sexfilis were the most strongly connected, with all sites in the network falling into a single SCC. Cellana spp. and P. meandrina each had approximately $60 \%$ of sites included in a SCC, but both show fragmentation with 7 and 6 SCCs respectively, ranging in size from 2-22 sites. This SCC pattern suggests low global connectivity but high local connectivity for these species. Medium and long dispersers showed larger connected components; $70 \%$ of parrotfish sites fell within two SCCs; $40 \%$ of $P$. porphyreus sites fell within two SCCs; $70 \%$ of C. strigosus sites, $55 \%$ of C. melampygus sites, and $40 \%$ of Panulirus sites fell within a single SCC. In contrast, only $26 \%$ of C. ignoblis sites fell within a single SCC. It is also important to note that the lower connectivity scores observed in longdispersing species likely reflect a larger scale of connectivity. Species with a shorter PLD are highly connected at reef and island levels but may show weaker connections between islands. Species with a longer PLD, such as trevally or spiny lobster, are likely more highly connected at inter-island scales which reflects the lower connectivity scores per island shown here. 
Minimum PLD was positively correlated with mean dispersal distance (e.g. an estimated

\section{II) Settlement to Moloka'i and other islands in the archipelago}

Different species showed different forward settlement proportion to adjacent islands (Fig. 4), although every species in the study group successfully settled back to Moloka'i. $P$. meandrina showed the highest percentage of island-scale local retention (82\%), while C. ignoblis showed the lowest (7\%). An average of $74 \%$ of larvae from short-dispersing species settled back to Moloka' $i$, as compared to an average of $41 \%$ of medium dispersers and $9 \%$ of long dispersers. A large proportion of larvae also settled to $\mathrm{O}^{\prime} \mathrm{ahu}$, with longer PLDs resulting in greater proportions, ranging from $14 \%$ of $O$. cyanea to $88 \%$ of $C$. ignoblis. Moloka' $i$ and $\mathrm{O}^{\prime}$ ahu were the most commonly settled islands by percentage. Overall, settlement from Moloka' $i$ to Lana' $i$, Maui, Kaho'olawe, and Hawai' $i$ was somewhat lower. Larvae of every species settled to Lana' $i$, and settlement to this island made up less than $5 \%$ of settled larvae across all species. Likewise, settlement to Maui made up less than $7 \%$ of settlement across species, with $P$. meandrina as the only species that had no successful paths from Moloka'i to Maui. Settlement to Kaho'olawe and Hawai' $i$ was less common, with the exception of Panulirus spp., which had $16 \%$ of all settled larvae on Hawai'i.

We also examined coast-specific patterns of rearward settlement proportion to other islands, discarding connections with a very low proportion of larvae $(<0.1 \%$ of total larvae of that species settling to other islands). Averaged across species, $83 \%$ of larvae settling to $\mathrm{O}^{\prime}$ ahu from Moloka' $i$ were spawned on the north shore of Moloka' $i$, with $12 \%$ spawned on the west shore (Fig S4). Spawning sites on the east and south shores contributed $<5 \%$ of all larvae settling to $\mathrm{O}^{\prime}$ 'ahu from Moloka 'i. The east and south shores of Moloka' $\mathrm{i}$ had the highest average percentage of larvae settling to Lana' $i$ from Moloka' $i$, at $78 \%$ and $20 \%$ respectively, and to Kaho'olawe from Moloka' $i$ at $63 \%$ and $34 \%$. Of the species that settled to Maui from Moloka' $i$, on average most were spawned on the east (53\%) or north (39\%) shores, as were the species that settled to Hawai'i Island from Moloka'i ( $22 \%$ east, $76 \%$ north). These patterns indicate that multiple coasts of Moloka' $i$ have the potential to export larvae to neighboring islands.

Temporal settlement profiles also varied by species (Fig. 5). Species modeled with moonphase spawning and relatively short settlement windows (Cellana spp. and C. ignoblis) were 
374 characterized by discrete settlement pulses, whereas other species showed settlement over a 375 broader period of time. Some species also showed distinctive patterns of settlement to other 376 islands; our model suggests specific windows when long-distance dispersal is possible, as well as 377 times of year when local retention is maximized (Fig. 5).

378

379

380

381

382

383

384

385

386

387

388

389

390

391

392

393

394

395

396

397

398

399

400

401

402

403

404

405

406

407

408

409

410

411

412

413

414

415

416

417

418

419

\section{III) Regional patterns of connectivity in Moloka'i coastal waters}

Within Moloka' $i$, our model predicts that coast-specific population structure is likely; averaged across all species, $84 \%$ of individuals settled back to the same coast on which they were spawned rather than a different coast on Moloka' $i$. Excluding connections with a very low proportion of larvae $\left(<0.1 \%\right.$ of total larvae of that species that settled to Moloka $\left.{ }^{\circ} i\right)$, we found that the proportion of coast-scale local retention was generally higher than dispersal to another coast, with the exception of the west coast (Fig 6A). The north and south coasts had a high degree of local retention in every species except for the long-dispersing Panulirus spp., and the east coast also had high local retention overall. Between coasts, a high proportion of larvae that spawned on the west coast settled on the north coast, and a lesser amount of larvae were exchanged from the east to south and from the north to east. With a few species-specific exceptions, larval exchange between other coasts of Moloka' $i$ was negligible.

We also calculated edge density, including all connections between coasts on Moloka'i regardless of settlement proportion (Fig. 6B). The eastern coast was particularly well-connected, with an edge density between 0.14 and 0.44 , depending on species. The southern shore showed high edge density for short and medium dispersers (0.16-0.39) but low for long dispersers $(<0.005)$. The north shore also showed relatively high edge density $(0.20$ on average), although these values were smaller for long dispersers. The west coast showed very low edge density, with the exceptions of $O$. cyanea $(0.37)$ and $P$. sexfilis $(0.13)$. Virtually all networks that included two coasts showed lower edge density. One exception was the east/south shore network, which had an edge density of 0.10-0.65 except for Cellana spp. Across species, edge density between the south and west coasts was 0.12 on average, and between the east and west coasts was 0.04 on average. Edge density between north and south coasts was particularly low for all species $(<0.05)$, a divide that was especially distinct in Cellana spp. and P. meandrina, which showed zero realized connections between these coasts. Although northern and southern populations are potentially weakly connected by sites along the eastern ( $P$. meandrina) or western (Cellana spp.) shores, our model predicts very little, if any, demographic connectivity.

To explore patterns of connectivity on a finer scale, we pooled sites into regions (as defined in Fig. 1) in order to analyze relationships between these regions. Arranging model output into node-edge networks clarified pathways and regions of note, and revealed several patterns which did not follow simple predictions based on PLD (Fig. 7). Cellana spp. and $P$. meandrina showed the most fragmentation, with several SCCs and low connectivity between coasts. Connectivity was highest in $O$. cyanea and $P$. sexfilis, which had a single SCC containing all regions. Medium and long dispersers generally showed fewer strongly connected regions on the south shore than the north shore, with the exception of C. strigosus. P. porphyreus showed more strongly connected regions east of Kalaupapa but lower connectivity on the western half of the island.

Region-level networks showed both species-specific and species-wide patterns of connectivity (Fig. 8). With a few exceptions, sites along the eastern coast - notably, Cape Halawa and Pauwalu Harbor - showed relatively high betweenness centrality, and may therefore act as multigenerational pathways between north-shore and south-shore populations. In Cellana spp., Leinapapio Point and Mokio Point had the highest BC, while in high-connectivity $O$. cyanea and 
420 P. sexfilis, regions on the west coast had high BC scores. P. meandrina and $C$. strigosus showed 421 several regions along the south shore with high BC. For Cellana spp. and P. meandrina, regions 422 in the northeast had the highest out-degree, and therefore seeded the greatest number of other 423 sites with larvae (Fig. 8). Correspondingly, regions in the northwest (and southwest in the case of $424 P$. meandrina) showed the highest in-degree. For $O$. cyanea and $P$. sexfilis, regions on the 425 western and southern coasts showed the highest out-degree. For most species, both out-degree and in-degree were generally highest on the northern and eastern coasts, suggesting higher connectivity in these areas.

Several species-wide hotspots of local retention emerged, particularly East Kalaupapa

430

431

432

433

434

435

436

437

438 Peninsula/Leinaopapio Point, the northeast corner of Moloka' $i$, and the middle of the south shore. Some species also showed some degree of local retention west of Kalaupapa Peninsula. While some local retention was observed in the long-dispersing Caranx spp. and Panulirus spp., this amount was essentially negligible. In terms of source-sink dynamics, Ki'oko'o, Pu'ukaoku Point, and West Kalaupapa Peninsula, all on the north shore, were the only sites that consistently acted as a net source, exporting more larvae than they import (Fig. 8). Kaunakakai Harbor, Lono Harbor, and Mokio Point acted as net sinks across all species. Puko'o, Pauwalu Harbor, and Cape Halawa were either weak net sources or neither sources nor sinks, which corresponds to the high levels of local retention observed at these sites. Pala'au and Mo'omomi acted as either weak sinks or sources for short dispersers and as sources for long dispersers.

Only four networks showed regional cut-nodes, or nodes that, if removed, break a network into multiple weakly-connected components (Fig. S5). Cellana spp. showed two cutnodes: Mokio Point in northwest Moloka'i and La'au Point in southwest Moloka'i, which if removed isolated Small Bay and Lono Harbor, respectively. C. perspicillatus, and $S$. rubroviolaceus showed a similar pattern in regards to Mokio Point; removal of this node isolated Small Bay in this species as well. In C. ignoblis, loss of Pauwalu Harbor isolated Lono Harbor, and loss of Pala'au isolated Ilio Point on the northern coast. Finally, in Panulirus spp., loss of Leinaopapio Point isolated Papuhaku Beach, since Leinapapio Point was the only larval source from Moloka'i for Papuhaku Beach in this species.

IV) The role of Kalaupapa Peninsula in inter- and intra-island connectivity connectivity, especially in terms of long-distance dispersal. Out of all regions on Moloka'i, East Kalaupapa Peninsula was the single largest exporter of larvae to Hawai'i Island, accounting for $19 \%$ of all larvae transported from Moloka' $i$ to this island; West Kalaupapa Peninsula accounted for another $10 \%$. The Park also contributed $22 \%$ of all larvae exported from Moloka'i to O'ahu, and successfully exported a smaller percentage of larvae to Maui, Lana'i, and Kaho'olawe (Fig. 9). Kalaupapa was not marked as a cut-node for any species, meaning that full population breaks are not predicted in the case of habitat or population loss in this area. Nevertheless, in our model Kalaupapa exported larvae to multiple regions along the north shore in all species, as well as regions along the east, south, and/or west shores in most species networks (Fig. 9 and Fig. 10). The Park may play a particularly important role for long-dispersing species; settlement from Kalaupapa made up 18\% - 29\% of all successful settlement in Caranx spp. and Panulirus spp., despite making up only $12 \%$ of spawning sites included in the model. In C. strigosus, $S$. rubroviolaceus, and C. strigosus, Kalaupapa showed a particularly high out-degree, or number of outgoing connections to other regions, and West Kalaupapa was also one of the few regions on Moloka' $i$ that acted as a net larval source across all species (Fig. 8). Our study has also demonstrated that different regions of a marine protected area can potentially perform different 
466 roles, even in a small MPA such as Kalaupapa. Across species, the east coast of Kalaupapa

467 showed a significantly higher betweenness centrality than the west $(p=0.028)$, while the west

468 coast of Kalauapapa showed a significantly higher source-sink index than the east $(p=2.63 e-9)$.

\section{Discussion:}

470

471

472

473

474

475

476

477

478

479

480

481

482

483

484

485

486

487

488

489

490

491

492

493

494

495

496

497

498

499

500

501

502

503

504

505

506

507

508

\section{I) Effects of biological and physical parameters on connectivity}

We incorporated the distribution of suitable habitat, variable reproduction, variable PLD, and ontogenetic changes in swimming ability and empirical vertical distributions of larvae into our model to increase biological realism, and assess how such traits impact predictions of larval dispersal. The Wong-Ala et al. (2018) IBM provides a highly flexible model framework that can easily be modified to incorporate either additional species-specific data or entirely new biological traits. In this study, we included specific spawning seasons for all species, as well as spawning by moon phase for Cellana spp., P. meandrina, and C. ignoblis because such data was available for these species. It proved difficult to obtain the necessary biological information to parameterize the model, but as more data about life history and larval behavior become available, such information can be easily added for these species and others. Some potential additions to future iterations of the model might include density of reproductive-age adults within each habitat patch, temperature-dependent pelagic larval duration (Houde, 1989), ontogeneticdependent behavioral changes such as orientation and diel vertical migration (Fiksen et al., 2007; Paris, Chérubin, \& Cowen, 2007), pre-competency period, and larval habitat preferences as such information becomes available.

In this study, we have demonstrated that patterns of fine-scale connectivity around Moloka' $i$ are largely species-specific and can vary with life history traits, even in species with identical pelagic larval duration. For example, the parrotfish $S$. rubroviolaceus and $C$. perspicillatus show greater connectivity along the northern coast, while the goatfish $P$. porphyreus shows higher connectivity along the eastern half of the island. These species have similar PLD windows, but vary in dispersal depth and spawning season. Spawning season and timing altered patterns of inter-island dispersal (Fig. 5) as well as overall settlement success, which was slightly higher in species that spawned by moon phase (Fig. 2). While maximum PLD did appear play a role in the probability of rare long-distance dispersal, minimum PLD appears to be the main driver of average dispersal distance (Fig. 2). Overall, species with a shorter minimum PLD had higher settlement success, shorter mean dispersal distance, higher local retention, and higher local connectivity as measured by the amount and size of strongly connected components.

The interaction of biological and oceanographic factors also influenced connectivity patterns. Because mesoscale current patterns can vary substantially over the course of the year, the timing of spawning for certain species may be critical for estimating settlement (Wren et al., 2016; Wong-Ala et al. 2018). Intermittent ocean processes may influence the probability of local retention versus long-distance dispersal; a large proportion of larvae settled to $\mathrm{O}^{\prime} \mathrm{ahu}$, which is somewhat surprising given that in order to settle from Moloka' $\mathrm{i}$ to $\mathrm{O}^{\prime} \mathrm{ahu}$, larvae must cross the Kaiwi Channel (approx. $40 \mathrm{~km}$ ). However, the intermittent presence of mesoscale gyres may act as a stabilizing pathway across the channel, sweeping larvae up either the windward or leeward coast of O'ahu depending on spawning site. Likewise, in our model long-distance dispersal to Hawai'i Island was possible at certain times of the year due to a gyre to the north of Maui; larvae 
509 were transported from Kalaupapa to this gyre, where they were carried to the northeast shore of

510 Hawai'i (Fig. S6). Preliminary analysis also suggests that distribution of larval depth influenced

511 edge directionality and size of connected components (Fig. 7); surface currents are variable and

512 primarily wind-driven, giving positively-buoyant larvae different patterns of dispersal than

513 species that disperse deeper in the water column (Fig. S7).

514

515

516

517

518

519

520

521

522

523

524

525

526

527

528

529

530

531

532

533

534

535

536

537

538

539

540

541

542

543

544

545

546

547

548

549

550

551

552

553

554

\section{II) Model limitations and future perspectives}

Our findings have several caveats. Because fine-scale density estimates are not available for our species of interest around Moloka'i, we assumed that fecundity is equivalent at all sites. This simplification may lead us to under- or over-estimate the strength of connections between sites. Lack of adequate data also necessitated estimation or extrapolation from congener information for larval traits such as larval dispersal depth and PLD. Since it is difficult if not impossible to identify larvae to the species level without genetic analysis, we used genus-level larval distribution data (Boehlert \& Mundy 1996), or lacking that, an estimate of 50-100m as a depth layer that is generally more enriched with larvae (Boehlert et al., 1992, Wren \& Kobayashi, 2016). We also estimated PLD in several cases using congener-level data (see Table 1). While specificity is ideal for making informed management decisions about a certain species, past sensitivity analysis has shown that variation in PLD length does not greatly impact patterns of dispersal in species with a PLD of $>40$ days (Wren \& Kobayashi, 2016).

Although our MITgem current model shows annual consistency, it only spans two and a half years chosen as neutral state 'average' ocean conditions. It does not span any El Niño or La Niña (ENSO) events, which cause wide-scale sea-surface temperature anomalies and may therefore affect patterns of connectivity during these years. El Niño can have a particularly strong impact on coral reproduction, since the warm currents associated with these events can lead to severe temperature stress (Glynn \& D'Croz, 1990; Wood et al., 2016). While there has been little study to date on the effects of ENSO on fine-scale connectivity, previous work has demonstrated increased variability during these events. For example, Wood et al. (2016) showed a decrease in eastward Pacific dispersal during El Niño years, but an increase in westward dispersal, and Treml et al. (2008) showed unique connections in the West Pacific as well as an increase in connectivity during El Niño. While these effects are difficult to predict, especially at such a small scale, additional model years would increase confidence in long-term connectivity estimations. Additionally, with a temporal resolution of 24 hours, we could not adequately address the role of tides on dispersal, and therefore did not include them in the MITgcm. Storlazzi et al. (2017) showed that tidal forces did affect larval dispersal in Maui Nui, underlining the importance of including both fine-scale, short-duration models and coarser-scale, long-duration models in final management decisions.

We also limit our model's scope geographically. Our goal was to determine whether we could resolve predictive patterns at this scale relevant to management. Interpretation of connectivity output can be biased by spatial resolution of the ocean model, since complex coastal processes can be smoothed and therefore impact larval trajectories. To limit this bias, we focused mainly on coastal and regional connectivity on scales greater than the current resolution. We also used the finest-scale current products available for our study area, and our results show general agreement with similar studies of the region that use a coarser resolution (Wren et al., 2016) and a finer resolution (Storlazzi et al., 2018). Also, while knowledge of island-scale connectivity is important for local management, it does disregard potential connections from other islands. In our calculations of edge density, betweenness centrality, we included only settlement to Moloka' $i$, discarding exogenous sinks that would bias our analysis. Likewise, we cannot predict 
555 the proportion of larvae settling to other islands that originated from Moloka' $i$, or the proportion

556 of larvae on Moloka' $i$ that originated from other islands.

557 It is also important to note scale in relation to measures of connectivity; we expect that

558 long-dispersing species such as Caranx spp. and Panulirus spp. will show much higher measures

559 of connectivity when measured across the whole archipelago as opposed to a single island. The

560 cut-nodes observed in these species may not actually break up populations on a large scale due to

561 this inter-island connectivity. Nevertheless, cut-nodes in species with short- and medium-length

562 PLD may indeed mark important habitat locations, especially in terms of providing links

563 between two otherwise disconnected coasts. It may be that for certain species or certain regions,

564 stock replenishment relies on larval import from other islands, underscoring the importance of

565 MPA selection for population maintenance in the archipelago as a whole.

566 III) Implications for management

$567 \quad$ Clearly, there is no single management approach that encompasses the breadth of life

568 history and behavior differences that impact patterns of larval dispersal and connectivity (Toonen

569 et al., 2011, Holstein, Paris, \& Mumby, 2014). The spatial, temporal, and species-specific

570 variability suggested by our model stresses the need for multi-scale management, specifically

571 tailored to local and regional connectivity patterns and the suite of target species. Even on such a

572 small scale, different regions around the island of Moloka' $i$ can play very different roles in the

573 greater pattern of connectivity (Fig. 8); sites along the west coast, for example, showed fewer

574 ingoing and outgoing connections than sites on the north coast, and therefore may be more at risk

575 of isolation. Seasonal variation should also be taken into account, as mesoscale current patterns

576 (and resulting connectivity patterns) vary over the course of a year. Our model suggests species-

577 specific temporal patterns of settlement (Fig. 5); even in the year-round spawner O. cyanea, local

578 retention to Moloka' $i$ as well as settlement to $\mathrm{O}^{\prime}$ ahu was maximized in spring and early summer,

579 while settlement to other islands mostly occurred in late summer and fall.

$580 \quad$ Regions that show similar network dynamics may benefit from similar management

581 strategies. Areas that act as larval sources either by proportion of larvae (high source-sink index)

582 or number of sites (high out-degree) should receive management consideration. On Moloka' $i$,

583 across all species in our study, these sources fell mostly on the northern and eastern coasts.

584 Maintenance of these areas is especially important for downstream areas that depend on

585 upstream populations for a source of larvae, such as those with a low source-sink index, low in-

586 degree, and/or low local retention. Across species, regions with the highest betweenness

587 centrality scores fell mainly in the northeast (Cape Halawa and Pauwalu Harbor). These areas

588 should receive consideration as potentially important intergenerational pathways, particularly as

589 a means of connecting north-coast and south-coast populations, which showed a lack of

590 connectivity both in total number of connections (edge density) and proportion of larvae. Both of

591 these connectivity measures were included because edge density includes all connections, even

592 those with a very small proportion of larvae, and may therefore include rare dispersal events that

593 are of little relevance to managers. Additionally, edge density comparisons between networks

594 should be viewed with the caveat that these networks do not necessarily have the same number

595 of nodes. Nevertheless, both edge density and proportion show very similar patterns, and include

596 both demographically-relevant common connections as well as rare connections that could

597 influence genetic connectivity.

598 Management that seeks to establish a resilient network of spatially managed areas should

599 also consider the preservation of both weakly-connected and strongly-connected components, as

600 removal of key cut-nodes (Fig. S5) breaks up a network. Sites within a SCC have more direct 
601 connections and therefore may be more resilient to local population loss. Care should be taken to 602 preserve breeding populations at larval sources, connectivity pathways, and cut-nodes within a 603 SCC, since without these key sites the network can fragment into multiple independent SCCs 604 instead of a single stable network. This practice may be especially important for species for 605 606 which we estimate multiple small SCCs, such as Cellana spp. or P. meandrina.

Kalaupapa Peninsula emerged as an important site in Moloka'i population connectivity, acting as a larval source for other regions around the island. The Park seeded areas along the north shore in all species, and also exported larvae to sites along the east and west shores in all species except $P$. meandrina and Cellana spp. Additionally, it was a larval source for sites along the south shore in the fishes C. perspicillatus, S. rubroviolaceus, and C. strigosus as well as Panulirus spp. Western Kalaupapa Peninsula was one of only three regions included in the analysis (the others being Ki'oko'o and Pu'ukaoku Point, also on the north shore) that acted as a net larval source across all species. Eastern Kalaupapa Peninsula was particularly highly connected, and was part of a strongly connected component in every species. The Park also

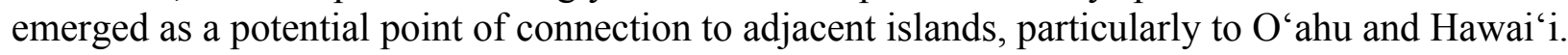
Expanding the spatial scale of our model will further elucidate Kalaupapa's role in the greater pattern of inter-island connectivity.

In addition to biophysical modeling, genetic analyses can be used to identify persistent population structure of relevance to managers (Cowen et al., 2000; Casey et al., 2016). Our finding that exchange among islands is generally low in species with a short- to medium-length PLD agrees with population genetic analyses of marine species in the Hawaiian Islands (Bird et al., 2007; Rivera et al., 2011; Toonen et al., 2011, Concepcion, Baums, \& Toonen, 2014). On a finer scale, we predict some level of shoreline-specific population structure for most species included in the study (Fig. 6). Unfortunately, genetic analyses to date have been performed over too broad a scale to effectively compare to these fine-scale connectivity predictions around Moloka' $i$ or even among locations on adjacent islands. These model results justify such small scale genetic analyses because there are species, such as the coral $P$. meandrina, for which the model predicts clear separation of north-shore and south-shore populations which should be simple to test using genetic data. To validate these model predictions with this technique, more fine-scale population genetic analyses are needed.

\section{Conclusions:}

632

633

634

635

636

637

638

639

640

641

642

643

644

The maintenance of demographically connected populations is important for conservation. In this study, we contribute to the growing body of work in biophysical connectivity modeling, focusing on a region and suite of species that are of relevance to resource managers. Furthermore, we demonstrate the value of quantifying fine-scale relationships between habitat sites via graph-theoretic methods. Multispecies network analysis revealed persistent patterns that can help define region-wide practices, as well as species-specific connectivity that merits more individual consideration. We demonstrate that connectivity is influenced not only by PLD, but also by other life-history traits such as spawning season, moonphase spawning, and ontogenetic changes in larval depth. High local retention of larvae with a short- or medium-length PLD is consistent with population genetic studies of the area. We also identify regions of management importance, including West Kalaupapa Peninsula, which acts as a consistent larval source across species; East Kalaupapa Peninsula, which is a strongly connected region in every species network, and Pauwalu Harbor/Cape Halawa, which may act as 
645 important multigenerational pathways. Connectivity is only one piece of the puzzle of MPA 646 effectiveness, which must also account for reproductive population size, long-term persistence, 647 and post-settlement survival (Burgess et al., 2014). That being said, our study provides a 648 quantitative roadmap of potential demographic connectivity, and thus presents an effective tool 649 for estimating current and future patterns of dispersal around Kalaupapa Peninsula and around 650 Moloka'i as a whole.

\section{Acknowledgements:}

The authors would like to thank Y Jia for MITgcm data, JATK Wong-Ala for work in developing the biophysical model, J Wren for advice concerning biophysical modeling, and E Brown for advice and support. Furthermore, we would like to thank members of the Moloka'i kūpuna and fishing community for their expertise and advice, especially to M Poepoe for help in parameterizing the model. Mahalo.

\section{References:}

Aeby GS. 2006. Baseline levels of coral disease in the Northwestern Hawaiian Islands. Atoll Research Bulletin 543:471-488.

Arkema KK, Abramson SC, Dewsbury BM. 2006. Marine ecosystem-based management: from characterization to implementation. Frontiers in Ecology and the Environment 4:525-532. doi:10.1890/15409295(2006)4[525:MEMFCT]2.0.CO;2.

Amante C, Eakins BW. 2009. Etopo1 1 arc-minute global relief model: Procedures, data sources and analysis. NOAA Technical Memorandum NESDIS NGDC-24:1-19. doi:10.7289/V5C8276M.

Beets J, Brown E, Friedlander A. 2010. Inventory of marine vertebrate species and fish-habitat utilization patterns in coastal waters off four national parks in Hawai‘i. Pacific Cooperative Studies Unit Technical Report 168. University of Hawai'i at Mānoa. Department of Botany. Honolulu, HI. 1-55

Bird CE, Holland BS, Bowen BW, Toonen RJ. 2007. Contrasting phylogeography in three endemic Hawaiian limpets (Cellana spp.) with similar life histories. Molecular Ecology 16:3173-3186. doi:10.1111/j.1365294X.2007.03385.x.

Boehlert GW, Watson W, Sun C. 1992. Horizontal and vertical distributions of larval fishes around an isolated oceanic island in the tropical Pacific. Deep-Sea Research 39:439-466. doi:10.1016/0198-0149(92)90082-5.

Boehlert GW, Mundy BC. 1996. Ichthyoplankton vertical distributions near Oahu, Hawai‘i, 1985-1986: data report. NOAA Technical Memoir. NMFS-SWSC-235: 1-148

Botsford LW, Brumbaugh DR, Grimes C, Kellner JB, Largier J, O’Farrell MR, Ralston S, Soulanille E, Wespestad V. 2009. Connectivity, sustainability, and yield: bridging the gap between conventional fisheries management and marine protected areas. Reviews in Fish Biology and Fisheries 19:69-95. doi:10.1007/s11160-008-9092-z.

Browman HI, Stergiou KI, Browman CHI, Cury PM, Hilborn R, Jennings S, Lotze HK, Mace PM, Murawski S, Pauly D, Sissenwine M, Zeller D. 2004. Perspectives on ecosystem-based approaches to the management of marine resources. Marine Ecology Progress Series 274:269-303. doi:10.3354/meps274269.

Burgess SC, Nickols KJ, Griesemer CD, Barnett LAK, Dedrick AG, Satterthwaite EV, Yamane L, Morgan SG, White JW, Botsford LW. 2014. Beyond connectivity: how empirical methods can quantify population persistence to improve marine protected-area design. Ecological Applications 24:257-270. doi:10.1890/130710.1 .

Calabrese JM, Fagan WF. 2004. A Comparison-Shopper's Guide to Connectivity Metrics. Frontiers in Ecology and the Environment 2:529-536. doi:10.1890/1540-9295(2004)002[0529:ACGTCM]2.0.CO;2.

Callan CK, Laidley CW, Ostrowski AC, Molnar A. 2012. Pacific Threadfin, Polydactylus sexfilis (moi) Hatchery Manual. Waimanalo, HI, USA: Center for Tropical and Subtropical Aquaculture.

Carson HS, López-Duarte PC, Rasmussen L, Wang D, Levin LA. 2010. Reproductive Timing Alters Population Connectivity in Marine Metapopulations. Current Biology 20:1926-1931. doi:10.1016/j.cub.2010.09.057. 
692

693

694

695

696

697

698

699

700

701

702

703

704

705

706

707

708

709

710

711

712

713

714

715

716

717

718

719

720

721

722

723

724

725

726

727

728

729

730

731

732

733

734

735

736

737

738

739

740

741

742

743

744

745

746

747

Casey J, Jardim E, Martinsohn JT. 2016. The role of genetics in fisheries management under the E.U. common fisheries policy. Journal of Fish Biology. 89:2755-2767. doi:10.1111/jfb.13151.

Castorani MC, Reed DC, Raimondi PT, Alberto F, Bell TW, Cavanaugh KC, Siegel DA, Simons RD. 2017. Fluctuations in population fecundity drive variation in demographic connectivity and metapopulation dynamics. Proceedings of the Royal Society of London B: Biological Sciences. 284. doi:10.1098/rspb.2016.2086.

Clarke TA. 1991. Larvae of nearshore fishes in oceanic waters near Oahu, Hawaii. Washington, D.C.: US Department of Commerce, National Oceanic and Atmospheric Administration, National Marine Fisheries Service. 1-19.

Coles SL, Brown BE. 2003. Coral bleaching - Capacity for acclimatization and adaptation. Advances in Marine Biology 46:183-223. doi:10.1016/S0065-2881(03)46004-5.

Concepcion GT, Baums IB, Toonen RJ. 2014. Regional population structure of Montipora capitata across the Hawaiian Archipelago. Bulletin of Marine Science 90:257-275. doi:10.5343/bms.2012.1109.

Corpuz GC. 1983. Life History Traits Influencing Vertical Zonation in the Hawaiian Intertidal Species of Cellana. Ph.D. dissertation. University of Hawai'i at Mānoa.

Costa BM, Kendall MS (eds.). 2016. Marine Biogeographic Assessment of the Main Hawaiian Islands. Bureau of Ocean Energy Management and National Oceanic and Atmospheric Administration. OCS Study BOEM 2016-035 and NOAA Technical Memorandum NOS NCCOS 214. 359 pp.

Cowen RK, Lwiza KMM, Sponaugle S, Paris CB, Olson DB. 2000. Connectivity of marine populations: Open or closed? Science 287:857-859. doi:10.1126/science.287.5454.857.

Cowen RK, Sponaugle S. 2009. Larval dispersal and marine population connectivity. Annual Review of Marine Science 1:443-466. doi:10.1146/annurev.marine.010908.163757.

Csardi G, Nepusz T. 2006. The igraph software package for complex network research. InterJournal, Complex Systems 1695. http://igraph.org.

Dawson MN, Hays CG, Grosberg RK, Raimondi PT. 2014. Dispersal potential and population genetic structure in the marine intertidal of the eastern North Pacific. Ecological Monographs 84(3):435-456. doi:10.1890/130871.1 .

DeMartini EE, DiNardo GT, Williams HA. 2003. Temporal changes in population density, fecundity, and egg size of the Hawaiian spiny lobster (Panulirus marginatus) at Necker Bank, Northwestern Hawaiian Islands. Fishery Bulletin 101(1): 22-31.

Elipot S, Lumpkin R, Perez RC, Lilly JM, Early JJ, Sykulski AM. 2016. A global surface drifter dataset at hourly resolution. Journal of Geophysical Research: Oceans 121. doi:10.1002/2016JC011716. doi:10.1002/2016JC011716.

Fiksen Ø, Jørgensen C, Kristiansen T, Vikebø F, Huse G. 2007. Linking behavioural ecology and oceanography:: larval behaviour determines growth, mortality and dispersal. Marine Ecology Progress Series 347:195-206.

Forsythe JW, Hanlon RT. 1997. Foraging and associated behavior by Octopus cyanea Gray, 1849 on a coral atoll, French Polynesia. Journal of Experimental Marine Biology and Ecology 209:15-31. doi:10.1016/S00220981(96)00057-3.

Friedlander A, Brown EK, Jokiel PL, Smith WR, Rodgers SK. 2003. Effects of habitat, wave exposure, and marine protected area status on coral reef fish assemblages in the Hawaiian archipelago. Coral Reefs 22:291-305. doi:10.1007/s00338-003-0317-2.

Friedlander AM, Aeby G, Brown E, Clark A, Coles S, Dollar S, Hunter C, Jokiel P, Smith J, Walsh B, Williams I, Wiltse W. 2005. The state of coral reef ecosystems of the Main Hawaiian Islands. pp. 222-269. In: J. Waddell (ed.), The state of coral reef ecosystems of the United States and Pacific freely associated states: 2005. NOAA Technical Memorandum NOS NCCOS 11. NOAA/NCCOS Center for Coastal Monitoring and Assessment's Biogeography Team.

Gaines SD, Lester SE, Grorud-Colvert K, Costello C, Pollnac R. 2010. Evolving science of marine reserves: New developments and emerging research frontiers. Proceedings of the National Academy of Sciences 107:18251-18255. doi:10.1073/pnas.1002098107.

Gillanders BM. 2005. Using elemental chemistry of fish otoliths to determine connectivity between estuarine and coastal habitats. Estuarine, Coastal and Shelf Science. 64:47-57. doi:10.1016/j.ecss.2005.02.005.

Glynn PW, D’Croz L. 1990. Experimental evidence for high temperature stress as the cause of El Niño-coincident coral mortality. Coral Reefs. 8:181-191. doi:10.1007/BF00265009.

Goodyear CP. 1996. Variability of fishing mortality by age: Consequences for maximum sustainable yield. North American Journal of Fisheries Management 16:8-13. doi:10.1577/15488675(1996)016<0008:VOFMBA >2.3.CO;2. 
748

749

750

751

752

753

754

755

756

757

758

759

760

761

762

763

764

765

766

767

768

769

770

771

772

773

774

775

776

777

778

779

780

781

782

783

784

785

786

787

788

789

790

791

792

793

794

795

796

797

798

799

800

801

802

Halpern BS, Warner RR. 2003. Matching marine reserve design to reserve objectives. Proceedings of the Royal Society of London B: Biological Sciences 270(1527):1871-1878. doi:10.1098/rspb.2003.2405.

Heukelem WV. 1973. Growth and life-span of Octopus cyanea (Mollusca: Cephalopoda). Journal of Zoology 169:299-315. doi:10.1111/j.1469-7998.1973.tb04559.x.

Hijmans RJ. 2016. geosphere: Spherical Trigonometry. R package version 1.5-5.

Hilborn R. 2011. Future directions in ecosystem based fisheries management: A personal perspective. Fisheries Research 108:235-239. doi:10.1016/j.fishres.2010.12.030.

Holstein DM, Paris CB, Mumby PJ. 2014. Consistency and inconsistency in multispecies population network dynamics of coral reef ecosystems. Marine Ecology Progress Series 499:1-18. doi:10.3354/meps10647.

Houde ED. 1989. Comparative growth, mortality, and energetics of marine fish larvae: temperature and implied latitudinal effects. Fishery Bulletin 87(3):471-495.

Huebert KB, Cowen RK, Sponaugle S. 2011. Vertical migrations of reef fish larvae in the Straits of Florida and effects on larval transport. Limnology and Oceanography. 56:1653-1666. doi:10.4319/1o.2011.56.5.1653.

Irisson J-O, Paris CB, Guigand C, Planes S. 2010. Vertical distribution and ontogenetic "migration" in coral reef fish larvae. Limnol. Oceanogr. 55:909-919. doi:10.4319/1o.2010.55.2.0909.

Jia Y, Calil PHR, Chassignet EP, Metzger EJ, Potemra JT, Richards KJ, Wallcraft AJ. 2011. Generation of mesoscale eddies in the lee of the Hawaiian Islands. Journal of Geophysical Research: Oceans. 116. doi: $10.1029 / 2011 \mathrm{JC} 007305$.

Johnson DW, Christie MR, Pusack TJ, Stallings CD, Hixon MA. 2018. Integrating larval connectivity with local demography reveals regional dynamics of a marine metapopulation. Ecology. 99:1419-1429. doi:10.1002/ecy.2343.

Jones GP, Srinivasan M, Almany GR. 2007. Population connectivity and conservation of marine biodiversity. Oceanography 20(3):100-111. doi:10.5670/oceanog.2007.33.

Kenyon J, Maragos J, Fenner D. 2011. The Occurrence of Coral Species Reported as Threatened in Federally Protected Waters of the US Pacific. Journal of Marine Biology 2011:e358687. doi:10.1155/2011/358687.

Kough AS, Paris CB, Butler IV MJ. 2013. Larval connectivity and the international management of fisheries. PLoS ONE 8(6) e64970. doi:10.1371/journal.pone.0064970.

Leis JM, Siebeck U, Dixson DL. 2011. How Nemo Finds Home: The Neuroecology of Dispersal and of Population Connectivity in Larvae of Marine Fishes. Integr Comp Biol. 51:826-843. doi:10.1093/icb/icr004.

Lester SE, Halpern BS, Grorud-Colvert K, Lubchenco J, Ruttenberg BI, Gaines SD, Airamé S, Warner RR. 2009. Biological effects within no-take marine reserves: a global synthesis. Marine Ecology Progress Series 384:33-46. doi:10.3354/meps08029.

Levin LA. 2006. Recent progress in understanding larval dispersal: new directions and digressions. Integrated and Comparative Biology 46:282-297. doi: 10.1093/icb/icj024.

Lipcius RN, Eggleston DB, Schreiber SJ, Seitz RD, Shen J, Sisson M, Stockhausen WT, Wang HV. 2008. Importance of Metapopulation Connectivity to Restocking and Restoration of Marine Species. Reviews in Fisheries Science 16:101-110. doi:10.1080/10641260701812574.

Longenecker K, Langston R, Barrett B. 2008. A compendium of life history information for some exploited Hawaiian reef fishes. Final Report prepared for Fisheries Local Action Strategy, Hawaii Division of Aquatic Resources. 67 pp.

Lowe M. 1995. The Main Hawaiian Islands Marine Resources Investigation (MHI-MRI): Integrated watershed and inshore fisheries management to conserve Hawaiian coastal fisheries ecosystems. Manuscript Collection of Country Statements and Background Papers. South Pacific Commission and Forum Fisheries Agency Workshop on the Management of South Pacific Inshore Fisheries. Noumea, New Caledonia. BP 76. Vol.II: 677-691.

Lowe RJ, Falter JL, Monismith SG, Atkinson MJ. 2009. A numerical study of circulation in a coastal reef-lagoon system. Journal of Geophysical Research: Oceans 114(C6). doi:10.4319/lo.2010.55.2.0909.

Luiz OJ, Allen AP, Robertson DR, Floeter SR, Kulbicki M, Vigliola L, Becheler R, Madin JS. 2013. Adult and larval traits as determinants of geographic range size among tropical reef fishes. Proceedings of the National Academy of Sciences 110:16498-16502. doi:10.1073/pnas.1304074110.

Lumpkin CF. 1998. Eddies and currents of the Hawaiian Islands. Ph.D. dissertation. University of Hawai' $i$ at Mānoa.

Marshall DJ, Krug PJ, Kupriyanova EK, Byrne M, Emlet RB. 2012. The Biogeography of Marine Invertebrate Life Histories. Annual Review of Ecology, Evolution, and Systematics 43:97-114. doi:10.1146/annurev-ecolsys102710-145004.

Peer] reviewing PDF | (2018:02:25164:2:0:NEW 24 Aug 2018) 
803

804

805

806

807

808

809

810

811

812

813

814

815

816

817

818

819

820

821

822

823

824

825

826

827

828

829

830

831

832

833

834

835

836

837

838

839

840

841

842

843

844

845

846

847

848

849

850

851

852

853

854

855

856

857

Marshall J, Adcroft A, Hill C, Perelman L, Heisey C. 1997. A finite-volume, incompressible Navier Stokes model for studies of the ocean on parallel computers. Journal of Geophysical Research: Oceans 102:5753-5766. doi:10.1029/96JC02775.

McClanahan TR, Mangi S. 2000. Spillover of exploitable fishes from a marine park and its effect on the adjacent fishery. Ecological Applications 10(6):1792-1805. doi:10.1890/10510761(2000)010[1792:SOEFFA]2.0.CO;2.

Meyer CG, Holland KN, Wetherbee BM, Lowe CG. 2000. Movement patterns, habitat utilization, home range size and site fidelity of whitesaddle goatfish, Parupeneus porphyreus, in a marine reserve. Environmental Biology of Fishes 59:235-242. doi: 10.1023/A:1007664813814.

Meyer CG, Papastamatiou YP, Clark TB. 2010. Differential movement patterns and site fidelity among trophic groups of reef fishes in a Hawaiian marine protected area. Marine Biology 157:1499-1511. doi:10.1007/s00227-010-1424-6.

Mitarai S, Siegel DA, Winters KB. 2008. A numerical study of stochastic larval settlement in the California Current system. Journal of Marine Systems 69:295-309. doi:10.1016/j.jmarsys.2006.02.017.

Mundy BC. 2005. Checklist of the fishes of the Hawaiian Archipelago. Bishop Museum Bulletins in Zoology 6:1704.

NOAA. 2009. Coral Reef Habitat Assessment for U.S. Marine Protected Areas: State of Hawaii: NW and Main Hawaiian Islands 1-55.

Pante E, Simon-Bouhet B. 2013. marmap: A Package for Importing, Plotting and Analyzing Bathymetric and Topographic Data in R. PLoS ONE 8(9): e73051. doi:10.1371/journal.pone.0073051.

Paris CB, Chérubin LM, Cowen RK. 2007. Surfing, spinning, or diving from reef to reef: effects on population connectivity. Marine Ecology Progress Series 347:285-300. doi:10.3354/meps06985.

Phillips BF, Booth JD, Cobb JS, Jeffs AG, McWilliam P. 2006. Larval and postlarval ecology. In: Phillips BF, editor. Lobsters: biology, management, aquaculture and fisheries. Oxford, UK: Blackwell Scientific Press p. 231-262. PMid:17081751. http://dx.doi. org/10.1002/9780470995969.ch7.

Pikitch EK, Santora C, Babcock EA, Bakun A, Bonfil R, Conover DO, Dayton P, Doukakis P, Fluharty D, Heneman B, Houde ED, Link J, Livingston PA, Mangel M, McAllister MK, Pope J, Sainsbury KJ. 2004. Ecosystembased fishery management. Science 305:346-347. doi:10.1126/science.1098222.

Polovina JJ, Moffitt RB. 1995. Spatial and Temporal Distribution of the Phyllosoma of the Spiny Lobster, Panulirus Marginatus, in the Northwestern Hawaiian Islands. Bulletin of Marine Science 56:406-417.

Portnoy DS, Hollenbeck CM, Renshaw MA, Cummings NJ, Gold JR. 2013. Does mating behaviour affect connectivity in marine fishes? Comparative population genetics of two protogynous groupers (Family Serranidae). Molecular Ecology 22:301-313. doi:10.1111/mec.12128.

R Core Team. 2017. R: A language and environment for statistical computing. R Foundation for Statistical Computing, Vienna, Austria. URL https://www.R-project.org/.

Richmond RH. 1987. Energetics, competency, and long-distance dispersal of planula larvae of the coral Pocillopora damicornis. Marine Biology 93(4): 527-533. doi:10.1007/BF00392790.

Rivera MAJ, Andrews KR, Kobayashi DR, Wren JLK, Kelley C, Roderick GK, Toonen RJ. 2011. Genetic Analyses and Simulations of Larval Dispersal Reveal Distinct Populations and Directional Connectivity across the Range of the Hawaiian Grouper (Epinephelus quernus). Journal of Marine Biology 2011:1-11. doi:10.1155/2011/765353

Scheltema RS. 1971. Larval dispersal as a means of genetic exchange between geographically separated populations of shallow-water benthic marine gastropods. The Biological Bulletin 140(2):284-322. doi:10.2307/1540075.

Schmidt-Roach S, Miller KJ, Woolsey E, Gerlach G, Baird AH. 2012. Broadcast Spawning by Pocillopora Species on the Great Barrier Reef. PLoS One 7. doi:10.1371/journal.pone.0050847.

Siegel DA, Kinlan BP, Gaylord B, Gaines SD. 2003. Lagrangian descriptions of marine larval dispersion. Marine Ecology Progress Series 260:83-96. doi:10.3354/meps26008.

Shanks AL. 2009. Pelagic Larval Duration and Dispersal Distance Revisited. The Biological Bulletin 216:373-385. doi:10.1086/BBLv216n3p373.

Slocombe DS. 1993. Implementing ecosystem-based management. Bioscience 43(9):612-622. doi:10.2307/1312148.

Smith M. 1993. An ecological perspective on inshore fisheries in the main Hawaiian Islands. Marine Fisheries Review 55:34-49.

Sponaugle S, Paris CB, Walter KD, Kourafalou V, D’Alessandro E. 2012. Observed and modeled larval settlement of a reef fish to the Florida Keys. Marine Ecology Progress Series 453:201-212. doi:10.3354/meps09641.

Peer] reviewing PDF | (2018:02:25164:2:0:NEW 24 Aug 2018) 
Stamoulis KA, Poti M, Delevaux JMS, Donovan MK, Friedlander A, and Kendall MS. 2016. Chapter 4: Fishes Reef Fish. pp. 156-196. In: Costa BM and Kendall MS (eds.). Marine Biogeographic Assessment of the Main Hawaiian Islands. Bureau of Ocean Energy Management and National Oceanic and Atmospheric Administration. OCS Study BOEM 2016-035 and NOAA Technical Memorandum NOS NCCOS 214. 359 pp.

Storlazzi CD, Brown EK, Field ME. 2006. The application of acoustic Doppler current profilers to measure the timing and patterns of coral larval dispersal. Coral Reefs 25:369. doi:10.1007/s00338-006-0121-x.

Storlazzi CD, van Ormondt M, Chen YL, Elias EPL. 2017. Modeling Fine-Scale Coral Larval Dispersal and Interisland Connectivity to Help Designate Mutually-Supporting Coral Reef Marine Protected Areas: Insights from Maui Nui, Hawaii. Frontiers in Marine Science 4:381. doi:10.3389/fmars.2017.00381.

Strathmann RR. 1993. Hypotheses on the Origins of Marine Larvae. Annual Review of Ecology and Systematics 24:89-117. doi:10.1146/annurev.es.24.110193.000513

Sudekum AE. 1984. Growth, feeding, and reproduction of Caranx ignoblis and Caranx melampygus from the Northwestern Hawaiian Islands. 1984. M.Sc. dissertation. University of Hawai'i at Mānoa.

Thorson G. 1950. Reproductive and larval ecology of marine bottom invertebrates. Biological Review 25:1-45. doi:10.1111/j.1469-185X.1950.tb00585.X.

Toonen RJ, Andrews KR, Baums IB, Bird CE, Concepcion GT, Daly-Engel TS, Eble JA, Faucci A, Gaither MR, Iacchei M, Puritz JB, Schultz JK, Skillings DJ, Timmers MA, Bowen BW. 2011. Defining boundaries for ecosystem-based management: a multispecies case study of marine connectivity across the Hawaiian Archipelago. Journal of Marine Biology 2011:1-13. doi:10.1155/2011/460173.

Treml EA, Halpin PN, Urban DL, Pratson LF. 2008. Modeling population connectivity by ocean currents, a graphtheoretic approach for marine conservation. Landscape Ecology 23:19-36. doi:10.1007/s10980-007-9138y.

Vaz AC, Richards KJ, Jia Y, Paris CB. 2013. Mesoscale flow variability and its impact on connectivity for the island of Hawai i. Geophysical Research Letters 40:332-337. doi:10.1029/2012GL054519.

Vikebø F, Jørgensen C, Kristiansen T, Fiksen Ø. 2007. Drift, growth, and survival of larval Northeast Arctic cod with simple rules of behaviour. Marine Ecology Progress Series 347:207-219. doi:10.3354/meps06979.

Wessel P, Smith WHF. 1996. A Global Self-consistent, Hierarchical, High-resolution Shoreline Database. Journal of Geophysical Research 101(\#B4):8741-8743. doi:10.1029/96JB00104.

Wong-Ala JATK, Comfort CM, Gove JM, Hixon MA, McManus MA, Powell BS, Whitney JL, Neuheimer AB. 2018. How life history characteristics and environmental forcing shape settlement success of coral reef fishes. Frontiers in Marine Science 5. doi:10.3389/fmars.2018.00065. Accepted.

Wood S, Paris CB, Ridgwell A, Hendy EJ. 2014. Modelling dispersal and connectivity of broadcast spawning corals at the global scale. Global Ecology and Biogeography 23:1-11. doi:10.1111/geb.12101.

Wood S, Baums IB, Paris CB, Ridgwell A, Kessler WS, Hendy EJ. 2016. El Niño and coral larval dispersal across the eastern Pacific marine barrier. Nature Communications 7. doi:10.1038/ncomms12571.

Wren JLK, Kobayashi DR. 2016. Exploration of the "larval pool": development and ground-truthing of a larval transport model off leeward Hawai'i. PeerJ 4:e1636. doi:10.7717/peerj.1636.

Wren JLK, Kobayashi DR, Jia Y, Toonen RJ. 2016. Modeled Population Connectivity across the Hawaiian Archipelago. PLOS ONE 11:e0167626. doi:10.1371/journal.pone.0167626. 


\section{Table $\mathbf{1}$ (on next page)}

Target taxa selected for the study, based on cultural, ecological, and/or economic importance.

PLD = pelagic larval duration. Short dispersers (3-25 day minimum PLD) in white, medium dispersers (30-50 day minimum PLD) in light gray, and long dispersers (140-270 day minimum PLD) in dark gray. Spawn season and timing from traditional ecological knowledge shared by cultural practitioners on the island. Asterisk indicates that congener-level data was used. (1) Bird et al., 2007; (2) Corpuz, 1983; (3) Schmidt-Roach et al., 2012; (4) Storlazzi, Brown, \& Field, 2006; (5) Richmond, 1987; (6) Heukelem, 1973; (7) Forsythe \& Hanlon, 1997; (8) Boehlert et al., 1992; (9) Callan et al., 2012; (10) Mundy, 2005; (11) Boehlert \& Mundy, 1996; (12) Luiz et al., 2013; (13) Sudekum, 1984; (14) Longenecker, Langston, \& Barrett, 2010; (15) DeMartini, DiNardo, \& Williams, 2003; (16) Polovina \& Moffitt, 1995; (17) Phillips et al., 2006. 
1

\begin{tabular}{|c|c|c|c|c|c|c|c|c|c|}
\hline $\begin{array}{c}\text { Common } \\
\text { name }\end{array}$ & $\begin{array}{c}\text { Scientific } \\
\text { name }\end{array}$ & $\begin{array}{l}\text { Spawn } \\
\text { type }\end{array}$ & $\begin{array}{l}\text { \# of larvae } \\
\text { spawned }\end{array}$ & $\begin{array}{l}\text { Spawning } \\
\text { day of year }\end{array}$ & $\begin{array}{l}\text { Spawning } \\
\text { hour of day }\end{array}$ & $\begin{array}{l}\text { Spawning } \\
\text { moon phase }\end{array}$ & $\begin{array}{l}\text { Larval depth } \\
\quad \text { (m) }\end{array}$ & $\begin{array}{l}\text { PLD } \\
\text { (days) }\end{array}$ & Habitat \\
\hline $\begin{array}{l}\text { 'Opihi/ } \\
\text { Limpet }\end{array}$ & Cellana spp. & Broadcast $^{1}$ & 861,300 & $\begin{array}{c}1-60 \& \\
121-181\end{array}$ & - & New & $0-5$ & $3-18^{1,2}$ & Intertidal $^{1}$ \\
\hline $\begin{array}{c}\text { Ko'a / } \\
\text { Cauliflower coral }\end{array}$ & $\begin{array}{l}\text { Pocillopora } \\
\text { meandrina }\end{array}$ & Broadcast $^{3}$ & $1,671,840$ & $91-151$ & 07:15-08:00 & Full & $0-5^{4}$ & $5-90 * 5$ & Reef \\
\hline $\begin{array}{l}\text { He'e / } \\
\text { Octopus }\end{array}$ & $\begin{array}{l}\text { Octopus } \\
\text { cyanea }\end{array}$ & Benthic $^{6}$ & $1,392,096$ & $1-360$ & - & - & $50-100$ & $21^{6}$ & Reef, rubble ${ }^{7}$ \\
\hline $\begin{array}{c}\text { Moi / } \\
\text { Pacific threadfin }\end{array}$ & $\begin{array}{l}\text { Polydactylus } \\
\text { sexfilis }\end{array}$ & Broadcast & $1,004,640$ & $152-243$ & - & - & $50-100^{8}$ & $25^{9}$ & Sand $^{10}$ \\
\hline $\begin{array}{l}\text { Uhu uliuli / } \\
\text { Spectacled parrotfish }\end{array}$ & $\begin{array}{c}\text { Chlorurus } \\
\text { perspicillatus }\end{array}$ & Broadcast & $1,404,792$ & $152-212$ & - & - & $0-120^{* 11}$ & $30 * 12$ & Reef $^{10}$ \\
\hline $\begin{array}{l}\text { Uhu palukaluka / } \\
\text { Reddlip parrotfish }\end{array}$ & $\begin{array}{c}\text { Scarus } \\
\text { rubroviolaceus }\end{array}$ & Broadcast & $1,404,792$ & $152-212$ & - & - & $0-120^{* 11}$ & $30 * 12$ & Rock, reef $^{10}$ \\
\hline $\begin{array}{c}\text { Kumu / } \\
\text { Whitesaddle Goatfish }\end{array}$ & $\begin{array}{l}\text { Parupeneus } \\
\text { porphyreus }\end{array}$ & Broadcast & $1,071,252$ & $32-90$ & - & - & $0-50 * 11$ & $41-56^{* 12}$ & Sand, rock, reef ${ }^{10}$ \\
\hline $\begin{array}{c}\text { Kole / } \\
\text { Spotted surgeonfish }\end{array}$ & $\begin{array}{l}\text { Ctenochaetus } \\
\text { strigosus }\end{array}$ & Broadcast & $1,177,200$ & $60-120$ & - & - & $50-100^{11}$ & $50 * 12$ & $\begin{array}{l}\text { Rock, reef, } \\
\text { rubble }{ }^{10}\end{array}$ \\
\hline $\begin{array}{c}\text { ‘Ōmilu / } \\
\text { Bluefin trevally }\end{array}$ & $\begin{array}{c}\text { Caranx } \\
\text { melampygus }\end{array}$ & Broadcast & $1,310,616$ & $121-243$ & - & - & $0-80 * 11$ & $140 * 13,14$ & Sand, reef ${ }^{10}$ \\
\hline $\begin{array}{c}\text { Ulua / } \\
\text { Giant trevally }\end{array}$ & $\begin{array}{l}\text { Caranx } \\
\text { ignoblis }\end{array}$ & Broadcast & $1,151,040$ & $152-243$ & - & Full & $0-80 * 11$ & $140^{13,14}$ & Sand, rock, reef $^{10}$ \\
\hline Ula / Spiny lobster & Panulirus spp. & Benthic $^{15}$ & $1,573,248$ & $152-243$ & - & - & $50-100^{16}$ & $270^{17}$ & Rock, pavement ${ }^{16}$ \\
\hline
\end{tabular}

2 


\section{Figure 1}

Spawning sites used in the model by species.

(A) C. perspicillatus, S. rubroviolaceus, P. porphyreus, C. strigosus, C. ignoblis, and C. melampygus, $\mathrm{n}=109$, (B) P. meandrina, $\mathrm{n}=129$, (C) O. cyanea and Panulirus spp., $\mathrm{n}=136$, (D) P. sexfilis, $\mathrm{n}=115$, and (E) Cellana spp., $\mathrm{n}=87$. Region names are displayed over associated spawning sites for fish species in (A). Regions are made up of 2 to 11 sites, grouped based on coastal geography and surrounding benthic habitat, and are designated in (A) by adjacent colored dots. Kalaupapa National Historical Park is highlighted in light green in $(A)$.

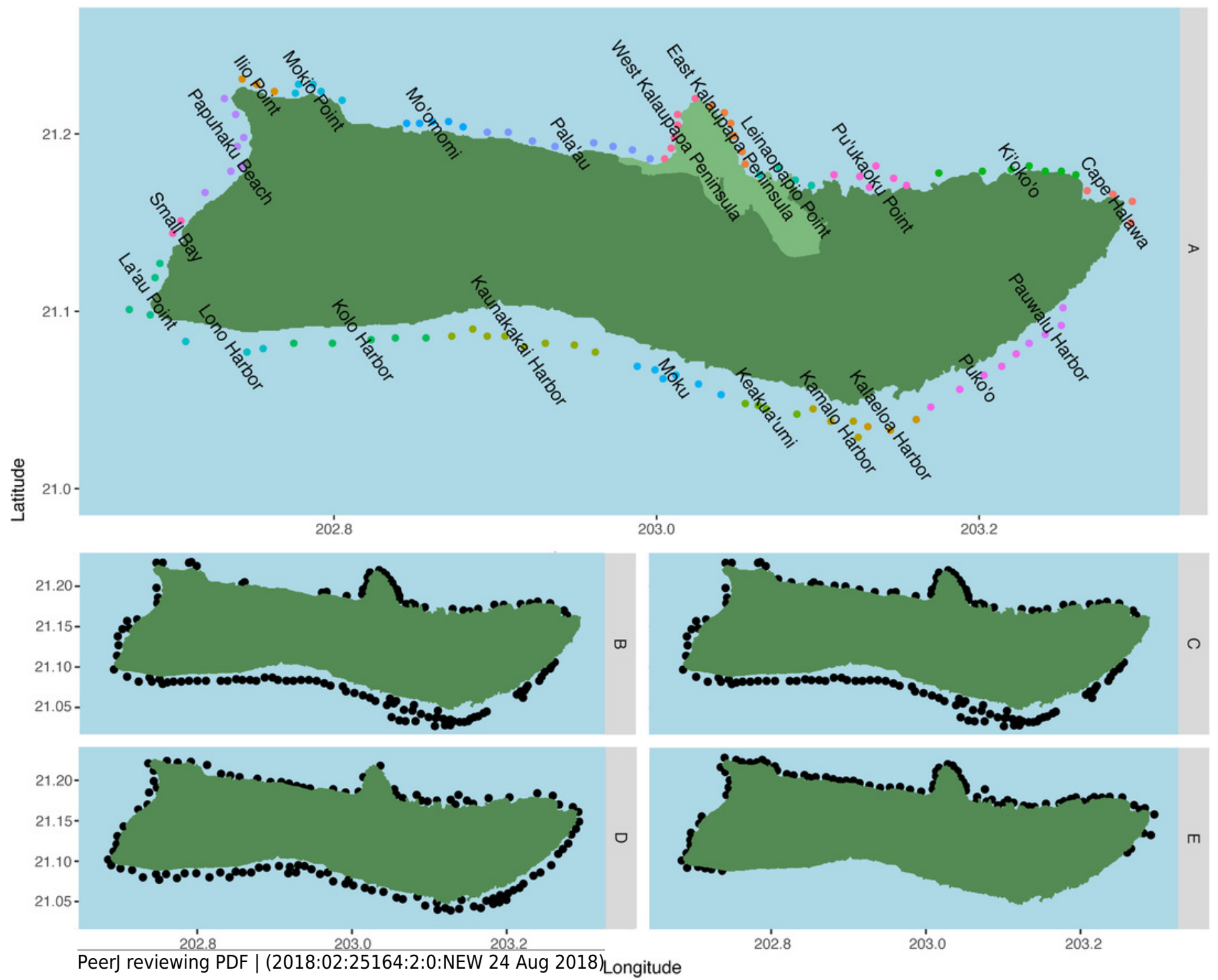




\section{Figure 2 (on next page)}

Summary statistics for each species network.

Summary statistics are displayed in order of increasing minimum pelagic larval duration from left to right. Heatmap colors are based on normalized values from 0-1 for each analysis. Successful settlement refers to the proportion of larvae settled out of the total number of larvae spawned. Local retention is measured as the proportion of larvae spawned from a site that settle at the same site. Shortest path is measured as the minimum number of steps needed to connect two sites. Strongly connected sites refers to the proportion of sites in a network that belong to a strongly connected component. Mean dispersal distance is measured in kilometers from spawn site to settlement site. 


\section{Figure 3}

Dispersal distance density kernels.

Dispersal distance is combined across species by minimum pelagic larval duration (PLD) length in days (short, medium, or long). Most short dispersers settle close to home, while few long dispersers are retained at or near their spawning sites.

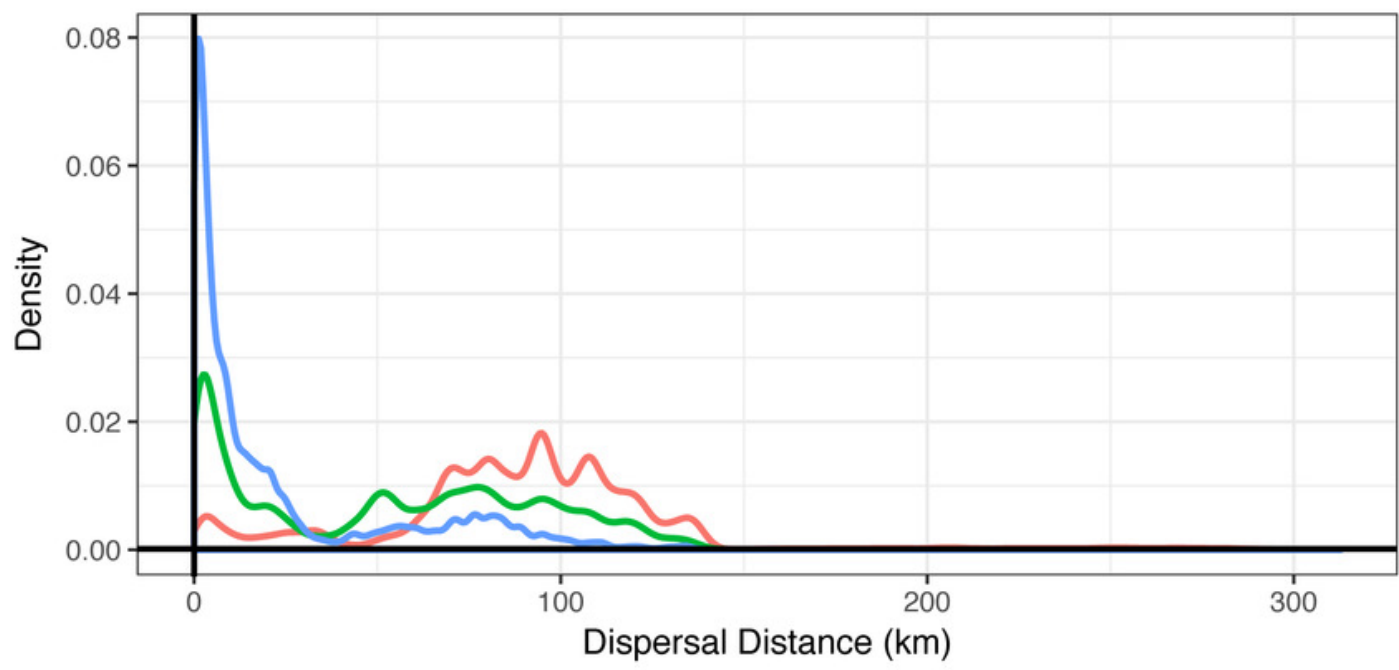

Minimum PLD Length

Long (140-270 days) Medium (30-50 days)

Short (3-25 days) 


\section{Figure 4}

Forward settlement from Moloka'i to other islands.

Proportion of simulated larvae settled to each island from Moloka'i by species, organized in order of increasing minimum pelagic larval duration from left to right.

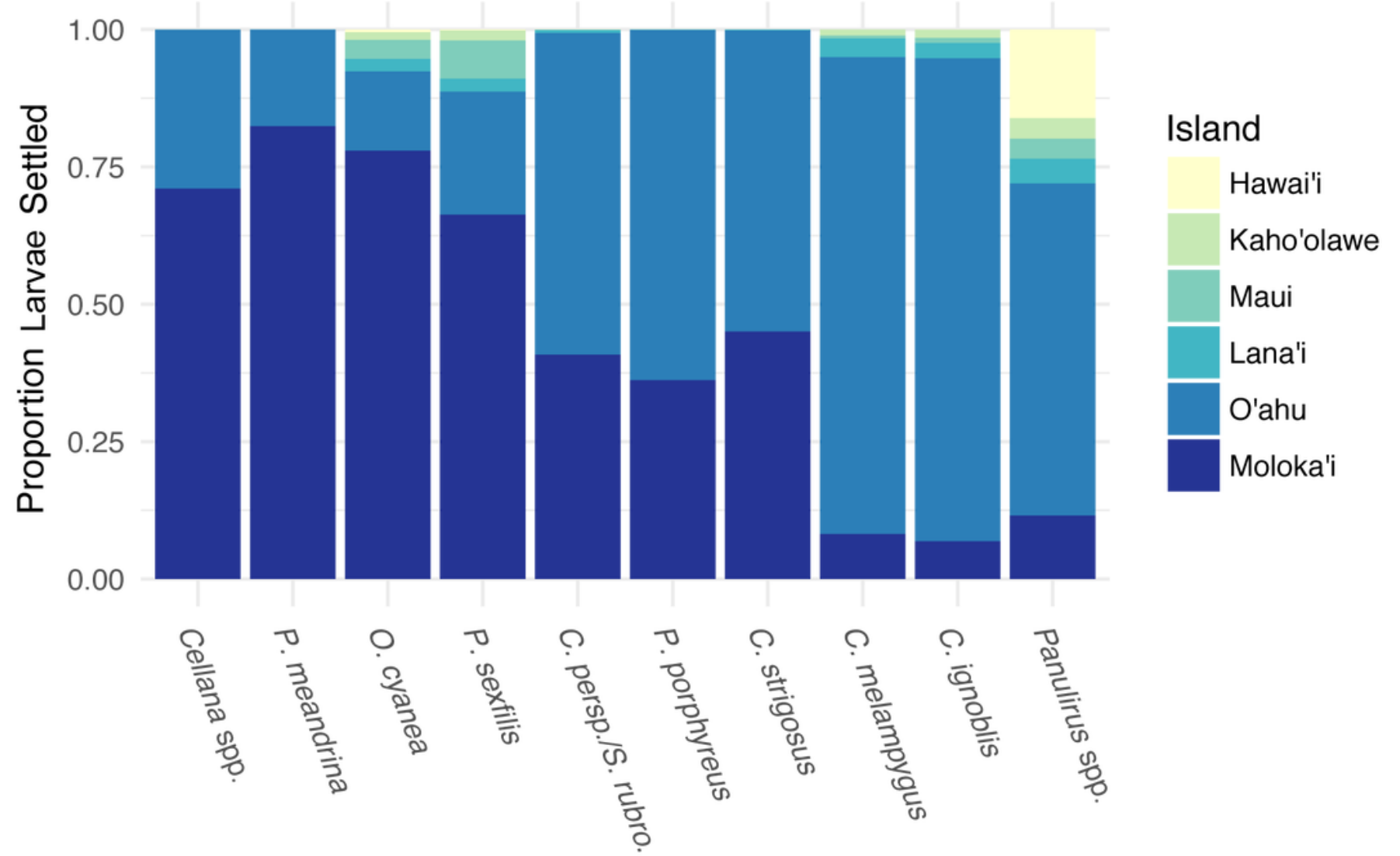

Species 


\section{Figure 5}

Species-specific temporal recruitment patterns.

Proportion densities of settlement to specific islands from Moloka'i based on day of year settled, by species. Rare dispersal events (e.g. Maui or Lana'i for Cellana spp.) appear as narrow spikes, while broad distributions generally indicate more common settlement pathways. 


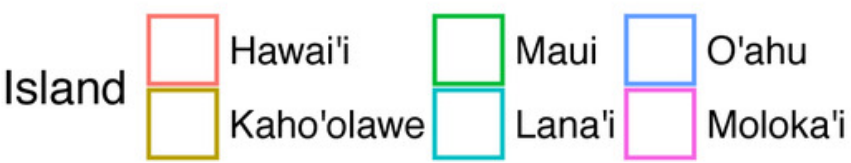

Cellana spp.
1.00
0.75
0.50
0.25
0.00

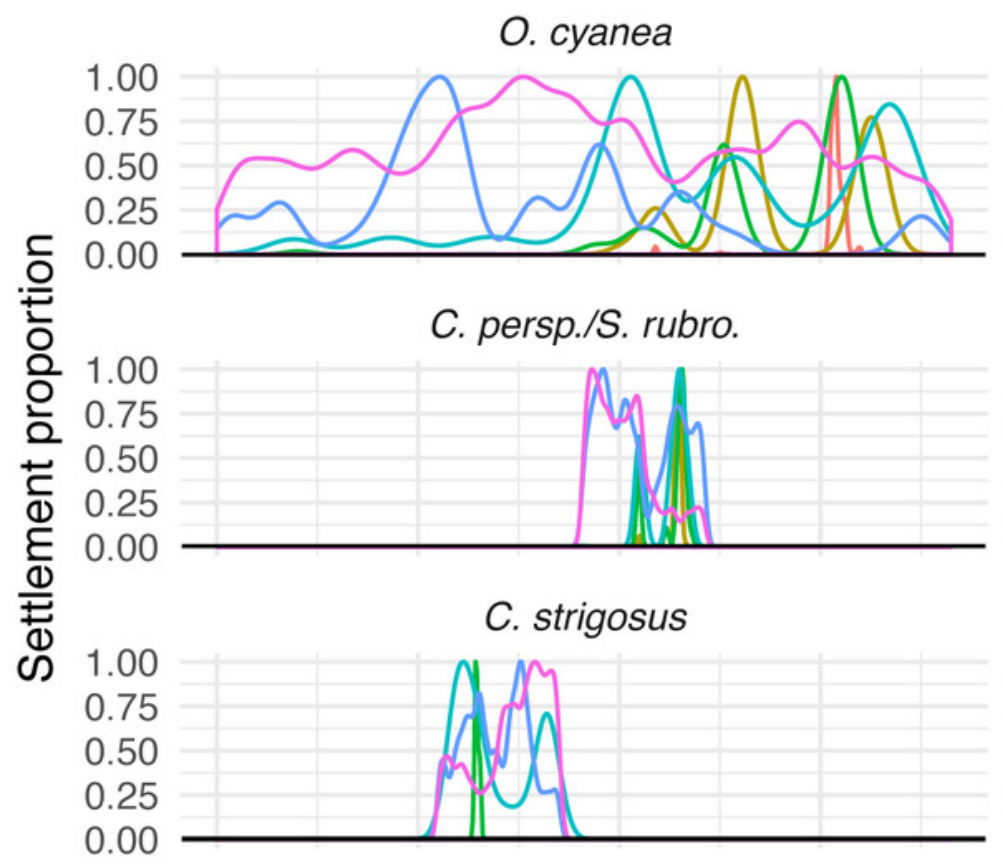

C. ignoblis

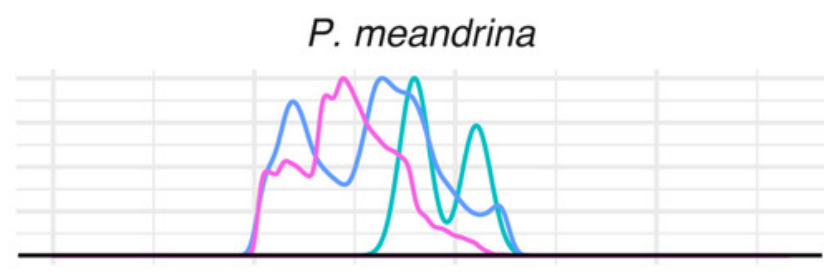

P. sexfilis
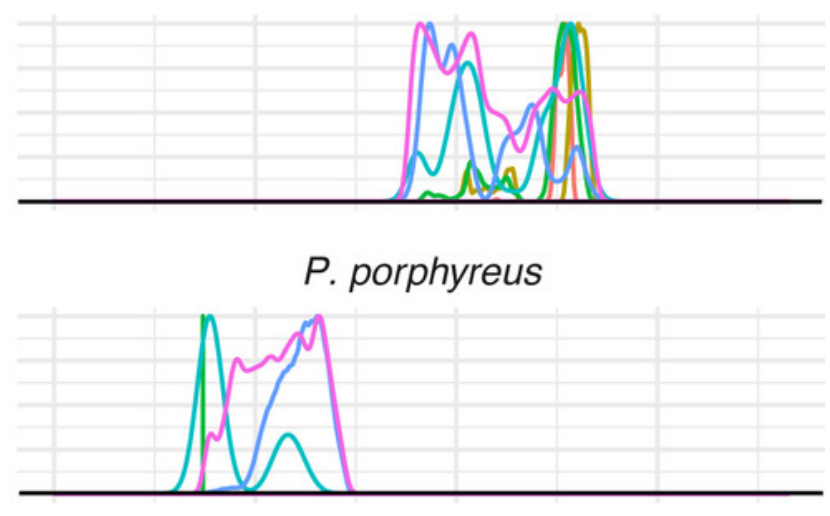

C. melampygus

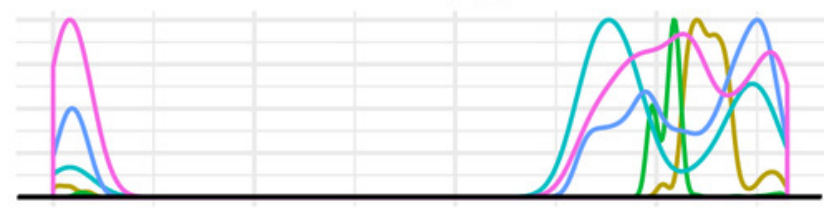

Panulirus spp.

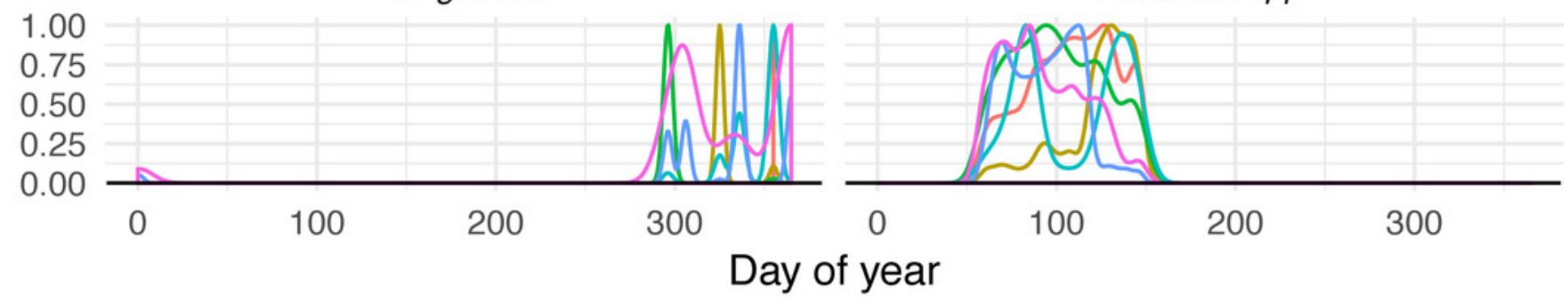




\section{Figure 6}

Coast-by-coast patterns of connectivity on Moloka'i.

(A) Average rearward settlement proportion by species per pair of coastlines, calculated by the number of larvae settling at site $s$ from site $o$ divided by all settled larvae at site $s$.

Directional coastline pairs (Spawn>Settlement) are ordered from left to right by increasing median settlement proportion. (B) Heatmap of edge density for coast-specific networks by species. Density is calculated by the number of all realized paths out of total possible paths, disregarding directionality. 


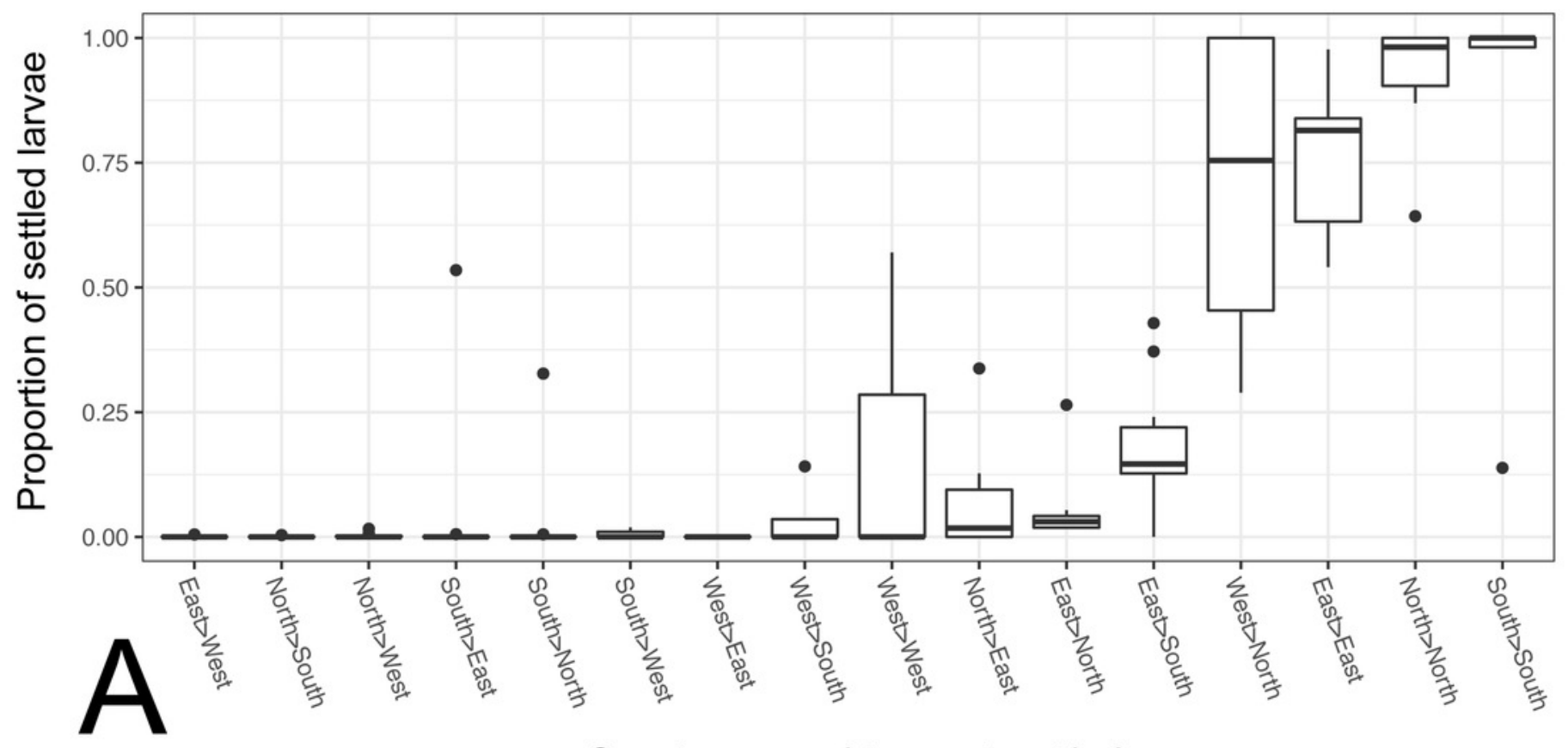

Coast spawned to coast settled

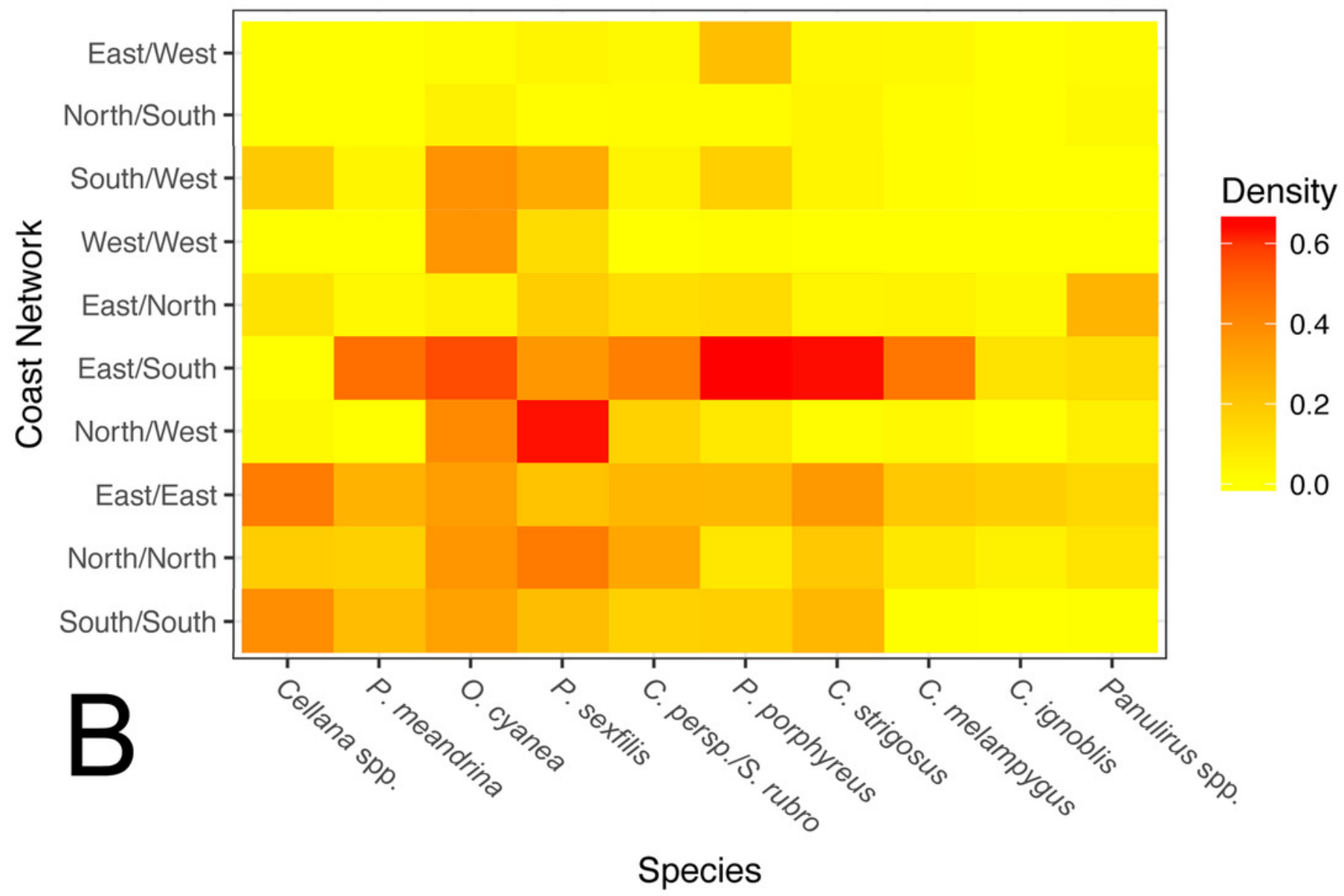




\section{Figure 7}

Moloka'i connectivity networks by species.

Graph-theoretic networks between regions around Moloka'i by species arranged in order of minimum pelagic larval duration. A-D: Short dispersers (3-25 days), E-G: medium dispersers (30-50 days), and $\mathbf{H - J : ~ l o n g ~ d i s p e r s e r s ~ ( 1 4 0 - 2 7 0 ~ d a y s ) . ~ N o d e ~ s i z e ~ r e f l e c t s ~ b e t w e e n n e s s ~}$ centrality of each region, scaled per species for visibility. Node color reflects out-degree of each region; yellow nodes have a low out-degree, red nodes have a medium out-degree, and black nodes have a high out-degree. Red edges are connections in a strongly connected component, while gray edges are not part of a strongly connected component (although may still represent substantial connections). Edge thickness represents log-transformed proportion of dispersal along that edge.

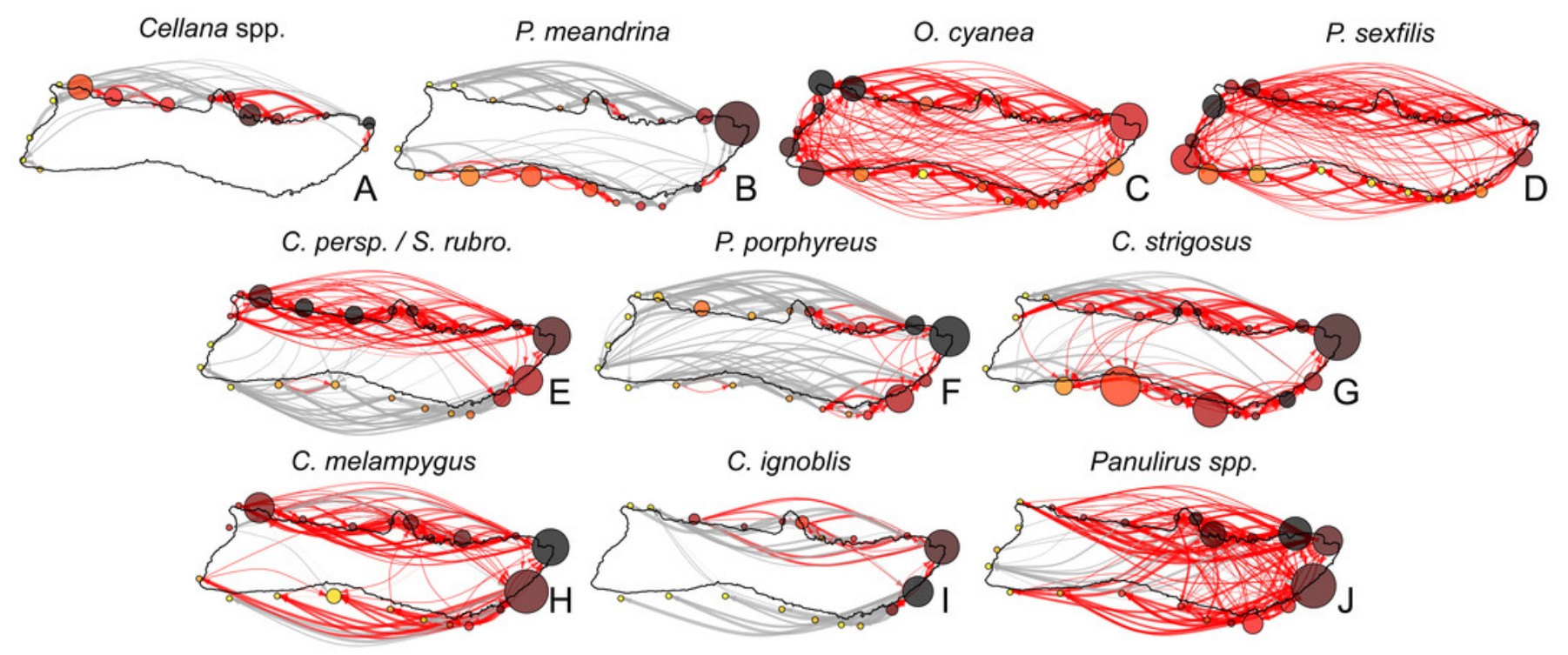




\section{Figure 8}

Region-level summary statistics across all species.

Betweenness centrality is a measure of the number of paths that pass through a certain region; a high score suggests potentially important multi-generation connectivity pathways. In-degree and out-degree refer to the amount of a node's incoming and outgoing connections. Betweenness centrality, in-degree, and out-degree have all been normalized to values between 0 to 1 per species. Local retention is measured as the proportion of larvae that settled back to their spawn site out of all larvae spawned at that site. Source-sink index is a measure of net export or import; negative values (blue) indicates a net larval sink, while positive values (red) indicates a net larval source. White indicates that a site is neither a strong source nor sink. Gray values for Cellana spp. denote a lack of suitable habitat sites in that particular region.
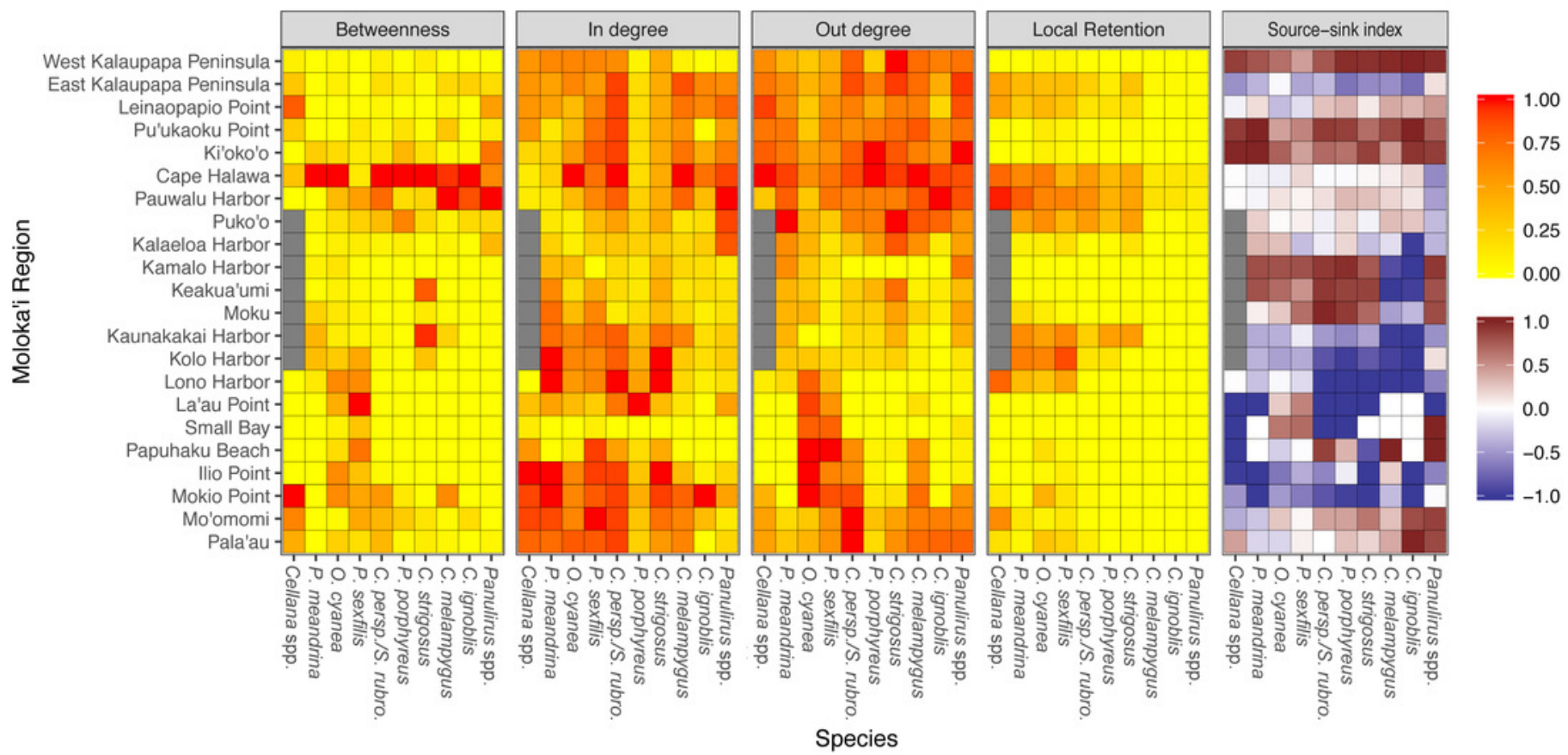


\section{Figure 9}

Connectivity matrix for larvae spawned on Kalaupapa Peninsula.

Includes larvae settled on Moloka'i (regions below horizontal black line) and those settled on other islands (regions above horizontal black line), spawned from either the east (E) or west (W) coast of Kalaupapa. Heatmap colors represent rearward proportion, calculated by the number of larvae settling at site $s$ from site $o$ divided by all settled larvae at site $s$. White squares indicate no dispersal along this path. 


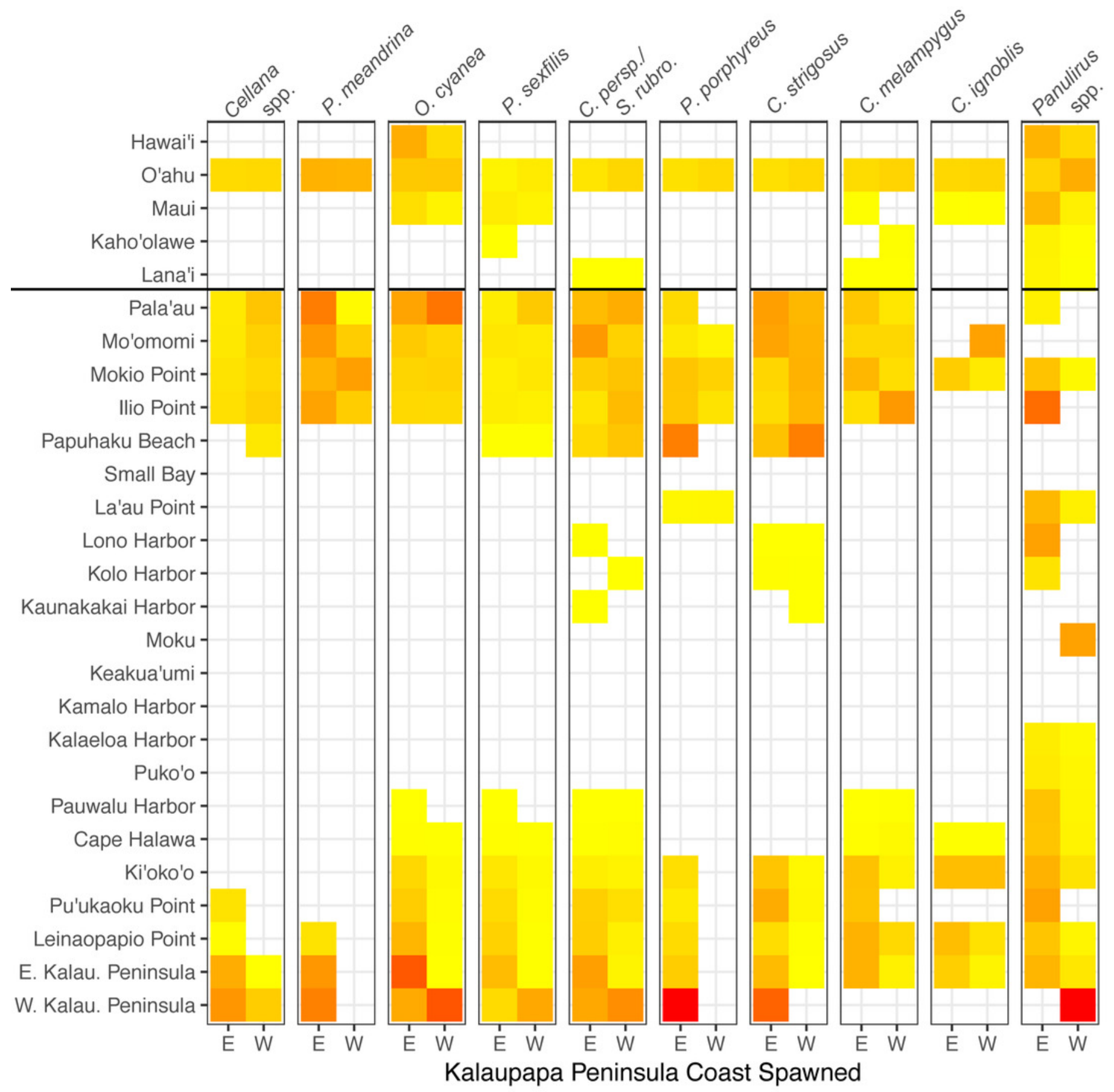

Proportion

$\begin{array}{lllll}0.1 & 0.2 & 0.3 & 0.4 & 0.5\end{array}$ 


\section{Figure 10}

Larval spillover from Kalaupapa National Historical Park.

Site-level dispersal to sites around Moloka'i from sites in the Kalaupapa National Historical Park protected area, by species. A-D: short dispersers (3-25 days), E-G: medium dispersers (30-50 days), and $\mathbf{H}$-J: long dispersers (140-270 days). Edge color reflects proportion of dispersal along that edge; red indicates higher proportion while yellow indicates lower proportion. Kalaupapa National Historical Park is highlighted in light green.

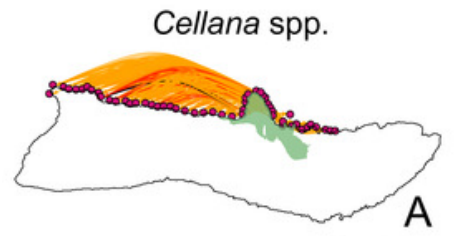

C. persp. / S. rubro.

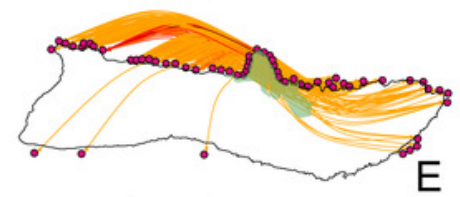

C. melampygus

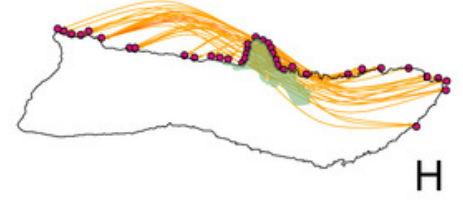

P. meandrina

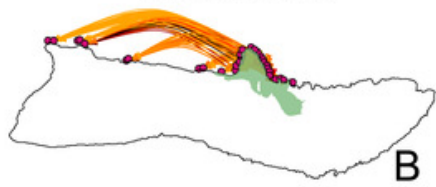

P. porphyreus

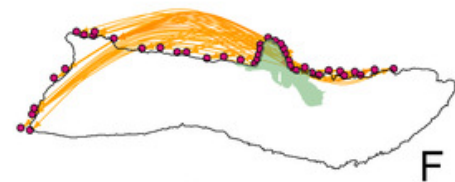

C. ignoblis

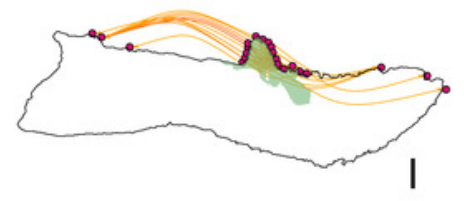

O. cyanea

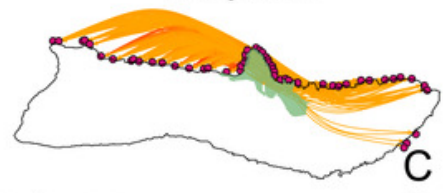

C. strigosus

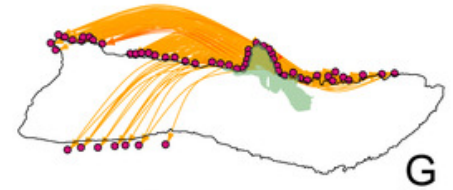

Panulirus spp.

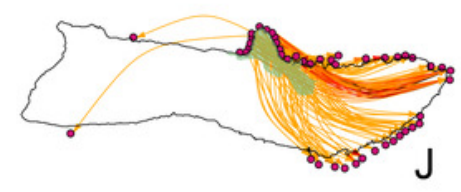

